\title{
Ultrastructural and histological changes induced by ivermectin in the ovary of Argas persicus after feeding
}

\author{
Hamdy, H.Swelim; Aleya, S.Marzouk;Ashraf,A.M.Montasser \\ Zoology department Faculty of science, Ain Shams University
}

\begin{abstract}
The ovarian wall of A.persicus consists of primary oocytes of three developmental stages namely, young, previtellogenic and vitellogenic in addition to interstitial cells . After feeding and mating, the three stages and interstitial cells, particularly funicle cells that carry oocytes, markedly increased in size and their cytoplasmic organelles exhibit notable changes correlated with yolk and egg shell formation .

The present study examined the hitological and ultrastructural aspects during the formation of yolk and egg shell. The first seem to originate from small vesicles derived from Golgi bodies, rough endoplasmic reticulum and mitochondrial cristae. The egg shell seems to develop from vesicles derived from Golgi bodies that fuse with the cell membrane and discharge their content into the extracellular space between basement membrane and tunica propria. Glycogen aggregates and lipid droplets are commonly observed between yolk spheres.

The injection of selected dose of ivermectin $(400 \mathrm{ug} / \mathrm{kg})$ prevented growth and development of oocytes. The ovary appeared studded with young and previtellogenic primary oocytes surrounding a narrow ovarian lumen or the ovarian wall, carrying oocytes, is stretched around a large fluid filled lumen. Surface microvilli of primary oocytes and coated vesicles underlying them became comparatively fewer. Mitochondria and rough endoplasmic reticulum became fewer, fragmented and finally degenerated in primary oocytes and funicle cells. Ivermectin interfered with the formation of yolk granules and egg shell. However, in the few formed vitellogenic oocytes, Golgi bodies were not affected. The egg shell appeared thinner with low electron density. The cytoplasm of funicle cells became highly vacuolated, its organelles, hardly distinguished and nuclei became swollen without definite nuclear membrane. Ivermectin completely prevented the formation of glycogen particles. Our results suggests that ivermectin causes partial blockage of the release of the vitellogenetic hormone that regulates vitellogenesis and other aspects of oogenesis as indicated by disrupted synthesis and uptake of yolk protein in the developing oocytes.
\end{abstract}

\section{Introduction}

The fowl tick Argas (Persicargas) persicus is a specific parasite of domestic and certain wild birds in parts of Asia,Europe, Africa and Australia (Nosek et al.,1980). The Argas toxins affect afferent and efferent nerve fibres and influence neuromuscular transmi -

ssion and thus cause fowl paralysis which increases in approximately direct proportion to the degree of tick infestation (Gothe et al.,1979). Numerous if not all argasid species produce more or less severe irritation when biting man (Yu Quan et al.,1995). 
A.persicus may occasionally bite man and transmit Bacillus anthracis (anthrax) to man (Deply and Kaweh, 1937) .Some Argas species infesting domestic birds were recorded to attack people causing severe pruritus, acute urticaria, inflammation with erythema, discoloration, bruise-like lesions, ulce rations, fever, weakness and anaphy lactic shock (Genchi,1992; Veraldi et al., 1998 ).

The macrocyclic lactone iverm ectin derived from the soil actinomycete Streptomyces avermitilis was introduced to the marketplace as an antiparasitic drug in 1981 (Campbell, 1989). It is now commercially used for the treatment and control of parasites in many domestic and laboratory animals and in man (Einstein et al .,1994). The studies on ivermectin were mainly confined to its effect on parasites, on biological parameters and routes of administration (Lancaster et al.,1982; Kaufman et al.,1986; Mahmood et al.,1991) . However, rare data dealt with the histological, histochemical or ultrastructural changes occurring in the internal organs of these parasites. The present study was undertaken to assess the effect induced by this drug on the internal organs of the tick A..persicus after feeding on hosts injected by the selected effective dose, which may provide an explanation for the mech anism of action of this drug .

\section{Materials And Methods}

Argas (Persicargas) persicus used in the present work originated from ticks obtained from a fowl house in Giza Governorate in Egypt . The domestic pigeon Columba livia domestica was used as a host. The ticks were reared in polyethylene tubes in an incubator at $28 \pm 1^{\circ} \mathrm{C}$ and relative humidity of $75 \%$. Pigeons were treated by a single subcutaneous injection in the femur region with Ivomec Injectable ${ }^{\circledR}$ (a formulation containing ivermectin in $1 \%$ concen tration, MSD Agvet, Division of Merck and Company, Rahway, N.J.).The effective dose was selected according to the results obtained from an inves tigative study on some biological parameters such as viability, sexual behavior, amounts of ingested blood, emitted coxal fluid, blood digestion and fertility (Montasser,2000). The used dose rate was $4000 u \mathrm{~g} / \mathrm{kg}$ pigeon weight versus control. Injections were made 2 and 7 days before ticks were allowed to feed . Tick feeding was also carried out 2 and 3 weeks after injection with the selected effective dose. Ovaries of the unfed females and fed females at 0, 2, 4 and 6 days after feeding were inves tigated. They were dissected in $0.7 \%$ $\mathrm{NaCl}$ solution, the dorsal integument was removed and internal organs were quickly fixed in Bouin's or calcium formol's fixatives, dehydrated in ethyl alcohol and then transferred to methyl benzoate for 24 hours to soften the tegument. They were then transferred to a solution of $2 \%$ celloidin in methyl benzoate for another 24 hours, cleared in benzol for 2 minutes, infilterated and embedded in paraplast. Serial sections were cut at $5 u$ m thick and stained with Mallory triple (MT) and haematoxylin and eosin (HX\&E) stains for general observations .

For transmission electron micro scopy, female ticks were dissected out under cold phosphate buffer adjusted to the $\mathrm{pH} 7.4$ and fixed for $2 \mathrm{hrs}$ in cold fresh buffered glutaraldehyde. Organs were washed in phosphate buffer, postfixed in cold buffered $1 \%$ osmium tetroxide for $1 \mathrm{hr}$ and washed again in fresh buffer for $0.5 \mathrm{hr}$. They were then dehydrated in ethanol, transferred through acetone for $0.5 \mathrm{hr}$, acetoneepoxy resin solution $(1: 1)$ for $1 \mathrm{hr}$, 
epoxy resin at room temperature for $2 \mathrm{hrs}$ and embedded in epoxy resin. Semi-thin sections $(1 u \mathrm{~m})$ were stained with methylene blue stain (MB) while ultrathin sections were stained in $2 \%$ uranyl acetate and lead citrate, exam ined and photographed using a Phillips transmission electron microscope (Phillips Co., Holland).

\section{Results}

The ovary in A. persicus is a hollow broad strap-like tube that lies transversely across the posterior half of the body.

The ovarian lumen is surrounded by the ovarian wall consisting of interstitial cells and primary oocytes in various stages of development (Figs. 1 21). The ovarian wall is covered externally by a thin layer tunica propria (ca. $0.3 u \mathrm{~m}$ thick) that consists of finely fibrillar material (Fig. 9a), separating the ovarian tissue from the haemol ymph. After feeding and mating, oocytes protrude into the haemocoel giving the ovary a grape-like appearance (Figs. 2 and 3).

Oocyte development in the present study is observed in unfed females and daily 6 days after feeding and mating. Histological examination reveals three developmental stages of primary oocytes namely, young oocytes, previt ellogenic oocytes and vitellogenic oocytes during this period. Oocytes of unfed ticks are oval, elongated or polygonal and are found facing the ovarian lumen (Figs. 1 and 6). From EM examination, their dense cytoplasm is found to contain few small ovoid or round mitochondria, free ribosomes and polyribosomes, very few cisternae of rough endoplasmic retic ulum in addition to numerous solitary and colonial forms of rickettsia-like microorganisms which are usually found infecting the different types of ovarian cells (Fig. 6 ). The nuclei are large with irregular or rounded margins (Fig.6 ). The nucleoplasm is occupied with finely granular euchromatin and dense masses of heterochromatin lying beneath the nuclear membrane in addition to a comparatively large nucleolus (ca. $4 u$ m diameter). After feeding, young oocytes measurements range between $15.4+0.8 \times 12.6+0.7 u \mathrm{~m}$ and $22.1 \pm 0.99 \times 16.6 \pm 0.7 u \mathrm{~m}$ (Table 1 ). Diameter of their nuclei also ranging between $8.3 \pm 0.4 u \mathrm{~m}$ and $11.7 \pm 0.48 u \mathrm{~m}$ (Table 1). No marked structural changes are observed directly after feeding except that the mitochondria become numerous and fill most of the oocyte cytoplasm (Fig. 7 ).

Phase 2 or the previtellogenic oocyte development is initiated by feeding and mating and is marked by a great cytoplasmic growth and lasts until the appearance of the vitelline granules (Figs.1-3). The mean diameter of oocytes in this stage ranges between $69.2 \pm 3.7 \times 53.7 \pm 3.1 u \mathrm{~m}$ and $85.3 \pm 3.2 \times$ $61.8 \pm 2.99 u \mathrm{~m}$ during the examined period (Table 1). In the unfed ticks, the cytoplasm is dense, granulated and contains numerous vacuoles, small mitochondria and numerous aggregates of rickettsia-like microorganisms (Figs.8a,b). Below the tunica propria, the surface of the oocyte membrane shows few microvilli (Fig. 9a) that become numerous and long after feeding (Figs.9b and 13). After feeding, several pits and coated vesicles that were formed due to the process of micropinocytosis are found in the peripheral zone of the oocyte cytoplasm (Figs.9b and 13). Microtubules are commonly observed as well as large number of microvilli and coated vesicles (Fig. 13). Cytoplasmic organelles become well developed within the few days after feeding. Mitochondria increase in their number 
(Fig. 10) and rough endoplasmic reticulum fills the cytoplasm and their cisternae appear as swollen vacuoles of short lengths (Figs. 13 and 14a). The Golgi complex markedly develops and increases in number (Fig.14a). Lipid droplets appear as groups scattered in the cytoplasm (Fig. 14b). The nucleus of the previtellogenic primary oocytes extremely enlarges within the few days following feeding (Fig.12). Its mean diameter ranges between $26.2 \pm 1.4 u \mathrm{~m}$ and 33.1 $\pm 0.97 u \mathrm{~m}$ (Table 1). The nucleoplasm is totally occupied with fine granules of euchromatin and a prominently large nucleolus Numerous perichromatin granules are aggregated in the nucleoplasm particularly beneath the nuclear membrane. Similar granules are also noticed outside the nuclear membrane (Fig. 11). The vitellogenic primary oocytes of $A$. persicus begin with the appearance of the first yolk granules in the cytoplasm and end with ovulation (Figs. 4,5 and15-18). Oocytes in this growth phase are characterized by the formation of yolk granules in addition to the deposition of egg shell. Yolk granules appear by the $4^{\text {th }}$ day after feeding (Fig.4). In this phase oocytes measure $170.6 \pm 12.4 \mathrm{x} \quad 117.9$ $\pm 8.77 u \mathrm{~m} 4$ days after feeding and $238.5 \pm 21.1 \times 159.5 \pm 12.7$ um 6 days after feeding (Table 1). The nucleus at the early stages of yolk deposition is obvious (Fig. 4), but in later stages it becomes diffused and difficult to detect among yolk bodies. Mean diameter of the nucleus in this phase ranges between $43.5 \pm 1.39 u \mathrm{~m}$ and $47.4 \pm 1.33 u \mathrm{~m}$ (Table 1). Yolk seems to originate from the small vesicles derived from Golgi bodies and rough endoplasmic reticulum (Figs. 16). Some coated vesicles that come from micropi nocytotic pits are seen fused into the multivesiculate bodies (Fig. 15). Multivesicular bodies gradually loss their internal membranes and eventually form large membrane limited reservoirs filled with fine granules (Fig. 16). Through repeated fusions between these reservoirs as well as small vesicles, derived from Golgi bodies and endoplasmic reticulum, large electron dense homogeneous yolk spheres are formed and gradually fill most of the oocyte cytoplasm (Fig. 18). By the $6^{\text {th }}$ day after feeding, i.e. in more advanced oocytes, there are numerous small and large vacuoles (Figs. 17 and 18). Mitochondria become fewer in number with less electron density and thinner cristae (Figs. 17 and 18). On the other hand glycogen particles increase and enormously aggregate in large rosettelike deposits that fill most of the cytoplasm between the yolk granules and lipid droplets increase in size and quantity as well (Figs.17 and18).

Mature oocytes (eggs) in the ovarian wall appear to be covered with shells (Fig. 5). Deposition of egg shell begins slightly later to the beginning of yolk formation (Fig. 17). Egg shell is synthesized mainly by the oocyte itself. It seems to develop from vesicles, derived from Golgi bodies, that pass towards and fuse with the cell membrane and/or microvilli discharging their content into the extracellular space between the basement membrane and tunica propria (Fig. 17). Released material are probably polymerized into dark patches that are firstly added near the surface of the oocyte then directed to the outside (Fig. 17). By the $6^{\text {th }}$ day of feeding, the mean thickness of the egg shell reaches ca. 2.2-2.8 um. Gradual increase in egg shell deposition results in stretching of the tunica propria giving the appearance of fewer distinct fibres (Fig. 17). During shell deposition microvilli reach their maximum length and appear as straight tubes (Fig. 17). 
The interstitial cells are small, irregular in shape and rest on the ovarian membrane between primary oocytes (Fig. 6). Their cytoplasm is extensively occupied by rickettsia-like microorganisms, few small mitochondria and vacuoles in addition to large oval or polygonal nuclei occupy most of the cell volume (Figs. 6 and 7). Their nuclei appear filled with euchromatin and heterochromatin as well .

The funicle cells carrying the previtellogenic oocytes in unfed females are irregular in shape (Fig.19) and collectively coated with the tunica propria covering the oocytes (Figs.20 and 21). They possess large nuclei that are occupied with fine chromatin granules and few chromatin aggregat ions mainly underlying the nuclear membrane (Fig.19). Their cytoplasm contains only few cisternae of rough endoplasmic reticulum, small mitocho ndria and little of the polyribosomes and microtubules. Funicle cells are fastened to each other by several desmosomes (Fig. 20). After feeding, their walls become highly convoluted (Fig. 21). Apical surfaces have numerous invaginations that are deeply inserted between oocyte microvilli (Fig. 20). After feeding, numerous microvilli are observed in the area connecting the oocyte with follicle cells and the cytoplasm appears highly occupied with numerous short cisternae of rough endoplasmic reticulum, several elongated mitochondria, few Golgi bodies and lysosomes (Figs. 20 and 21). Cytoplasmic areas near the connection with oocytes contain few of these organelles and numerous microtubules (Fig. 20) . The nuclei contain numerous patches of heterochromatin lying mainly under the nuclear membrane (Fig. 21).

\section{Effect of ivermectin on the structure of the developing oocytes:}

Considerable effects are noticed in the ovary of $A$. persicus following administration of a single subcutaneous dose of ivermectin $(400 \mathrm{ug} / \mathrm{kg})$ given to the host pigeon (Figs. 22-33). It mostly prevents growth and development of oocytes. The ovary appears studded with young phases of primary oocytes (Fig. 22). Previtellogenic phases are mainly from earlier development in the last nymphal instars. The ovarian lumen is filled with a fluid making the ovary more dilated and the ovarian wall stretched (Fig. 24). The sizes of oocytes, particularly young ones, and their nuclei were larger in ticks fed on untreated hosts than those fed on treated ones. Dimensions of young oocytes 4 and 6 days after feeding are signific antly higher $(p<0.01)$ in females fed on untreated hosts when compared to those fed on treated ones. The latter meas uring $14.1 \pm 0.4 \times 11.5 \pm 0.4 u \mathrm{~m}$ and $14.6 \pm 0.6 \times 10.1 \pm 0.4 u \mathrm{~m}$, respectively (Table 1). Mean diameter of nuclei 2, 4 and 6 days after feeding are signify cantly higher $(p<0.01)$ in females fed on untreated hosts than on treated ones measuring $9.32 \pm 0.3 u \mathrm{~m}, 8.54 \pm 0.23 u \mathrm{~m}$ and $8.8 \pm 0.17 u \mathrm{~m}$, respectively (Table 1). No obvious changes are observed in staining affinity with MT or methylene blue stains in young oocytes or their nuclei between ticks fed on untreated and treated hosts (Figs. 22 and 23). Electron micrographs show that the treatment causes disruption in some areas of the plasma membranes in addition to slight vacuolation in the cytoplasm (Figs. 26). Mitochondria are clearly noticed as in oocytes of ticks fed on untreated hosts but other organelles are rarely observed (Figs. 26).

Dimension of the previtellogenic phases of primary oocytes and their nuclei of ticks fed on untreated and treated hosts shows no significant difference $\quad(p>0.05) \quad($ Table 1). No 
marked changes are noticed in MT or methylene blue staining affinity of the previtellogenic phases and their nuclei between ticks fed on untreated and treated hosts (Figs. 22-25). However electron microscope reveals that the previtellogenic oocytes of ticks fed on treated hosts exhibit considerable alterations from those fed on untreated ones (Figs.28-29b). Microvilli surrou nding oocytes are also found as in the untreated group but with less density(Figs.17 and27). Coated and micropinocytotic vesicles below these microvilli are comparatively fewer. The cytoplasm appear less dense with fewer organelles. Mitochondria become fewer and smaller (Figs. 28 and 29b). The cristae of some mitochondria are fragmented, degenerated so the mitochondria look like round or oval vesicles containing dark granules and surrounded with double membranes (Fig.29b). Others are completely degenerated leaving only masses of granulated substance without limiting membrane. Some cytoplasmic areas particularly near funicle cells appear vacuolized (Fig. 28). The nuclei of oocytes at this stage did not show considerable changes as compared with those of untreated group besides the perichromatin granules that are released from oocyte nucleus are considerably fewer (Fig. 28).

Ivermectin greatly affects vitellogenesis that only appears in less than $1 / 10$ of the examined specimens, so it is difficult to statistically measure this kind of treated oocytes (Table 1). The cytoplasm appears loose and less electron dense than in ticks fed on untreated hosts. Most of the mitochondria are destructed, their cristae change into fine granular material and their matrices appear less dense (Figs. 30 and 31). Rough endop - lasmic reticulum become fewer giving the appearance of short vesicles with little ribosomes. Development of Golgi bodies is nearly unaffected by iverme ctin treatment. Vesicles of Golgi bodies, short cisternae of rough endopl -asmic reticulum and degenerated mitochondria still seem to share in yolk formation. By the $6^{\text {th }}$ day after feeding few membrane limited yolk spheres containing fine and less electron dense granules are formed. Fewer lipid droplets are observed in vitellogenic oocytes of ticks fed on treated hosts (Figs. 30 and 31). Ivermectin completely prevent forma tion of glycogen granules that are commonly observed as large rosette-like deposits in oocytes of ticks fed on untreated hosts.

Ivermectin considerably affect shell deposition, where only. . few coated vesicles containing moderately dense material are noticed near the oocyte membrane. They seem to disch arge their contents through exocytosis to the outside between microvilli and tunica propria. Microvilli are not stretched as in oocytes of ticks fed on untreated hosts. Egg shell appears thinner where its thickness measures about half of the oocyte of ticks fed on untreated hosts (Figs17 and31).

Impact of ivermectin on funicle cells is also drastic (Fig. 32 and 33). They become intensively vacuolized, hypertrophied and greatly damaged. Cytoplasmic organelles become fragm ented and could be hardly distinguished. Nuclei appear as swollen irregular masses without definite nuclear memb ranes (Figs. 32 and 33). Invaginations and desmosomes normally found near the oocyte-funicle cells attachment site are very few as compared with the condition of ticks fed on untreated hosts (Fig20 and.33). 
Table 1: Dimensions of the oocytes and their nuclei at differend developmental stages of Argas (P.) persicus fed on untreated and ivermectin treated hosts with a single dose of subcutaneous injection of $400 \mathrm{ug} / \mathrm{kg} \mathrm{0,2,4}$ and 6 days after feeding .

\begin{tabular}{|c|c|c|c|c|}
\hline \multirow{2}{*}{$\begin{array}{l}\text { Time after } \\
\text { Feeding }\end{array}$} & \multicolumn{2}{|c|}{ Mean oocyte dimension ( um) \pm SE (Range) } & \multicolumn{2}{|c|}{ Mean nucleus diameter (um) $+\mathrm{SE}$ (Range) } \\
\hline & Untreated & Treated & Untreated & Treated \\
\hline \multicolumn{5}{|l|}{ Zero Day } \\
\hline Young Oocyte & $\begin{array}{l}15.4 \pm 0.8 \times 12.6 \pm 0.7 \\
(10.5-24.0 \times 9.0-24.0)\end{array}$ & $\begin{array}{c}14.3 \pm 0.3 \times 12.2 \pm 0.3 \\
(10.5-18 \times 9-15)\end{array}$ & $\begin{array}{c}8.3 \pm 0.4 \\
(6-12)\end{array}$ & $\begin{array}{c}8.14 \pm 0.25 \\
(6.6-9)\end{array}$ \\
\hline $\begin{array}{l}\text { Previtellogenic } \\
\text { Phase }\end{array}$ & $\begin{array}{l}69.2 \pm 3.7 \times 53.7 \pm 3.1 \\
(45-111 \times 30-105)\end{array}$ & $\begin{array}{c}69.0 \pm 3.7 \times 49.7 \pm 3.0 \\
(33-108 \times 24-78)\end{array}$ & $\begin{array}{c}26.2 \pm 1.4 \\
(15-42)\end{array}$ & $\begin{array}{l}23.0 \pm 0.92^{*} \\
(12-33)\end{array}$ \\
\hline $\begin{array}{l}\text { Vitellogenic } \\
\text { Phase }\end{array}$ & - & - & - & - \\
\hline \multicolumn{5}{|l|}{ Two Days } \\
\hline Young Oocyte & $\begin{array}{c}18.4 \pm 0.7 \times 14.5 \pm 0.5 \\
(12-22.5 \times 12-18)\end{array}$ & $\begin{array}{l}15.3 \pm 0.5 \times 12.8 \pm 0.5 \\
(12-19.5 \times 10.5-16.5)\end{array}$ & $\begin{array}{c}11.17+0.35 \\
(9-13.5)\end{array}$ & $\begin{array}{l}9.32+0.30^{* * *} \\
(6.9-12)\end{array}$ \\
\hline $\begin{array}{l}\text { Previtellogenic } \\
\text { Phase }\end{array}$ & $\begin{array}{c}69.9 \pm 3.5 \times 54.1 \pm 2.8 \\
(42-105 \times 33-78)\end{array}$ & $\begin{array}{c}67.1 \pm 2.5 \times 55.9 \pm 2.0 \\
(45-102 \times 36-75)\end{array}$ & $\begin{array}{c}26.7 \pm 0.87 \\
(18-33)\end{array}$ & $\begin{array}{c}29.1 \pm 1.28 \\
(21-45)\end{array}$ \\
\hline $\begin{array}{l}\text { Vitellogenic } \\
\text { Phase }\end{array}$ & - & - & - & - \\
\hline \multicolumn{5}{|l|}{ Four Days } \\
\hline Young Oocyte & $\begin{array}{c}26.2 \pm 1.2 \times 20.6 \pm 1.04 \\
(18-34 \times 12-33)\end{array}$ & $\begin{array}{l}>14.1 \pm 0.4 \times 11.5 \pm 0.4 * * \\
(10.5-18 \times 10.5-18)\end{array}$ & $\begin{array}{c}13.3 \pm 0.58 \\
(7.5-16.5)\end{array}$ & $\begin{array}{l}8.54 \pm 0.23 * * \\
(7.5-10.5)\end{array}$ \\
\hline $\begin{array}{l}\text { Previtellogenic } \\
\text { Phase }\end{array}$ & $\begin{array}{c}83.3 \pm 3.18 \times 58.4 \pm 2.4 \\
(57-117 \times 36-78)\end{array}$ & $\begin{array}{c}86.1 \pm 3.9 \times 62.2 \pm 3.5 \\
(57-120 \times 39-99)\end{array}$ & $\begin{array}{c}31.8 \pm 0.73 \\
(27-39)\end{array}$ & $\begin{array}{l}30.4 \pm 1.18 \\
(24-39)\end{array}$ \\
\hline $\begin{array}{l}\text { Vitellogenic } \\
\text { Phase }\end{array}$ & $\begin{array}{c}170.6 \pm 12.4 \times 117.9 \pm 8.77 \\
(102-276 \times 75-240) \\
\end{array}$ & - & $\begin{array}{c}43.5 \pm 1.39 \\
(36-57)\end{array}$ & - \\
\hline \multicolumn{5}{|l|}{ Six Days } \\
\hline Young Oocyte & $\begin{array}{c}22.1 \pm 0.99 \times 16.6 \pm 0.7 \\
(18-33 \times 12-24)\end{array}$ & $\begin{array}{c}>14.6 \pm 0.6 \times 10.1 \pm 0.4^{* *} \\
(12-18 \times 9.12)\end{array}$ & $\begin{array}{c}11.7 \pm 0.48 \\
(9-16.5)\end{array}$ & $\begin{array}{l}8.8 \pm 0.17^{* * *} \\
(8.4-9.6)\end{array}$ \\
\hline $\begin{array}{l}\text { Previtellogenic } \\
\text { Phase }\end{array}$ & $\begin{array}{c}85.3 \pm 3.2 \times 61.8 \pm 2.99 \\
(60-120 \times 42-84)\end{array}$ & $\begin{array}{c}81.0 \pm 4.03 \times 53.7 \pm \\
2.57 \\
(48-108 \times 39-75)\end{array}$ & $\begin{array}{c}33.1 \pm 0.97 \\
(30-42)\end{array}$ & $\begin{array}{c}31.5 \pm 1.28 \\
(22.5-42)\end{array}$ \\
\hline $\begin{array}{l}\text { Vitellogenic } \\
\text { Phase }\end{array}$ & $\begin{array}{c}238.5 \pm 21.1 \times 159.5 \pm 12.7 \\
(111-432 \times 87-300)\end{array}$ & - & $\begin{array}{l}47.4 \pm 1.33 \\
(38-60)\end{array}$ & - \\
\hline
\end{tabular}

* Significant difference $(\mathrm{P}<0.05)$, ** Highly significant difference $(\mathrm{P}<0.01)$ 


\section{Ultrastructural and histological changes induced.......}

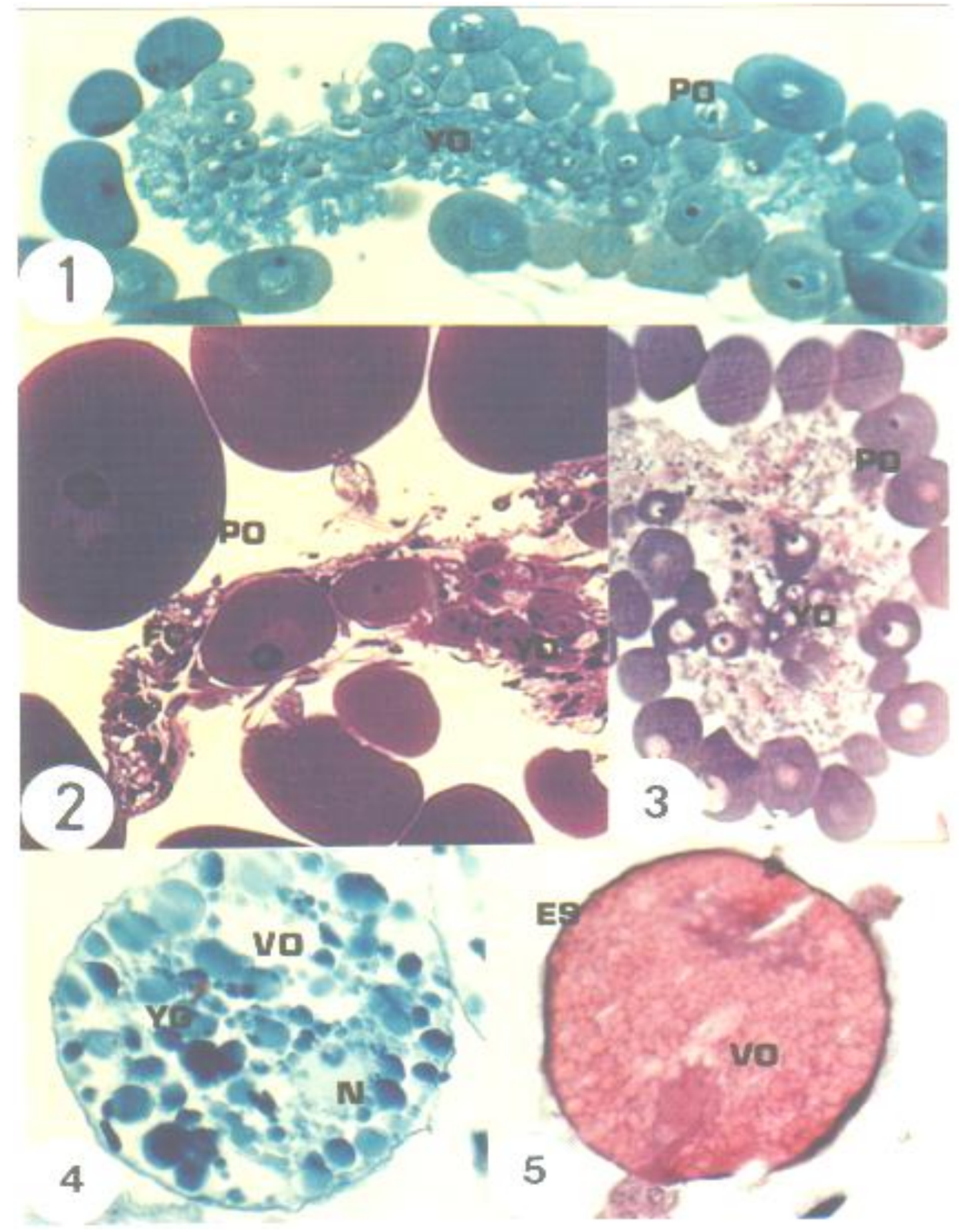

Fig. 1: Transverse section passing through the ovary of unfed A. persicus showing young (YO) and previtellogenic (PO) stages of primary oocytes (MT stain, x 160).

Fig. 2: Semithin section of the ovary of A. persicus directly after feeding showing young (YO) and previtellogenic (PO) stages of primary oocytes. FC, funicle cells (MB stain, x 200).

Fig. 3: As in Fig. 1 but 2 days after feeding (Hx-E stain, x 125).

Fig. 4: Transverse section passing through vitellogenic oocyte (VO) in the ovary of A. persicus 4 days after feeding showing the formation of yolk granules (YG), N, nucleus (MT stain, $x$ 200).

Fig. 5: As in Fig.4 but 6 days after feeding showing the formation of egg shell (ES) (Hx-E stain, $x$ 200). 

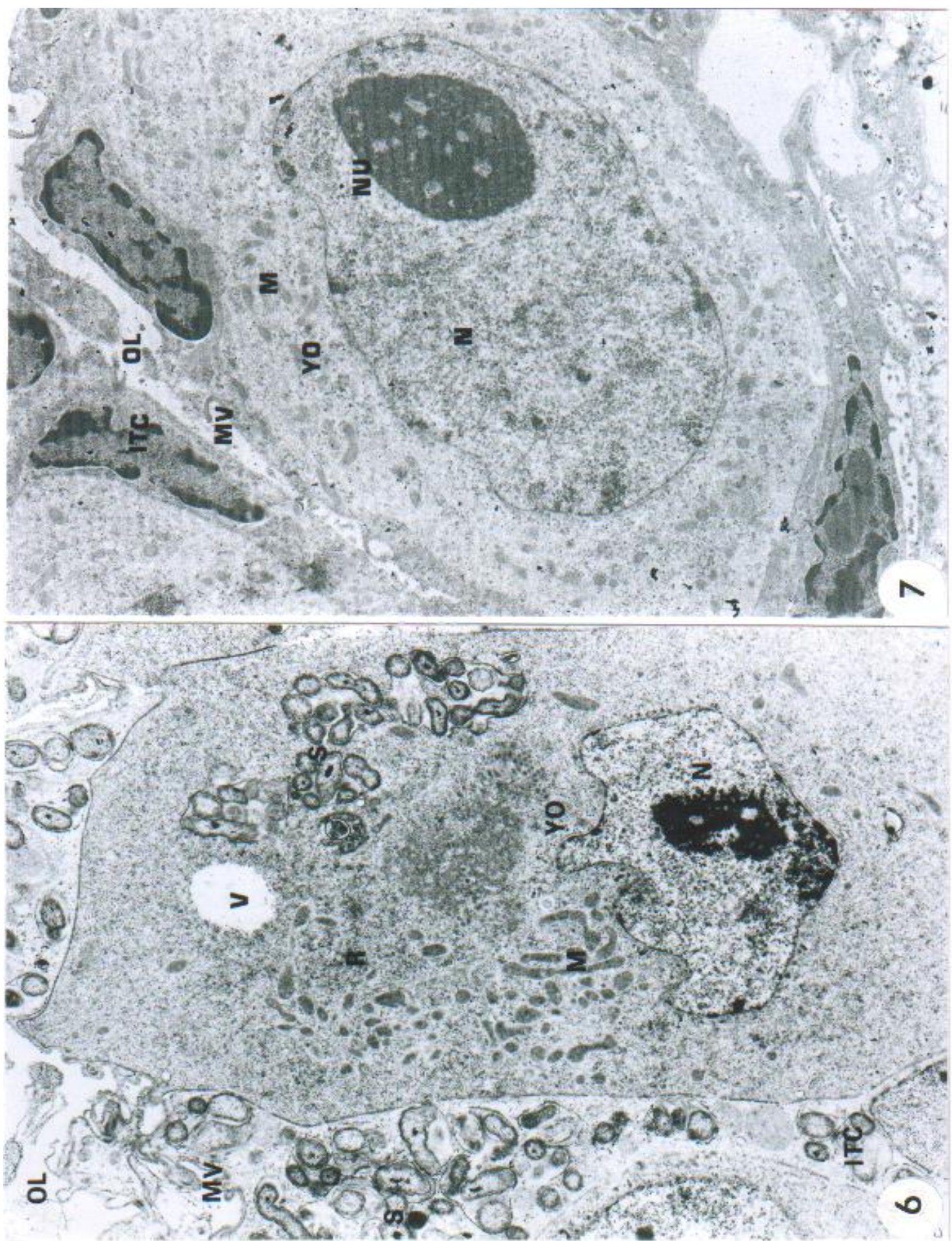

Fig. 6: Electron micrograph of young oocyte (YO) of unfed A. persicus. ITC, interstitial cells; M, mitochondria; MV, microvilli; N, nucleus; OL, ovarian lumen; R, ribosomes; S, rickettsia-like microorganisms; V, vacuole (x 9750).

Fig. 7: Electron micrograph of young oocyte (YO) of A. persicus directly after feeding showing mitochondria $(\mathrm{M})$, nucleus $(\mathrm{N})$, nucleolus (NU), ovarian lumen (OL), microvilli (MV) and interstitial cells (ITC) (x 13000). 


\section{Ultrastructural and histological changes induced.......}
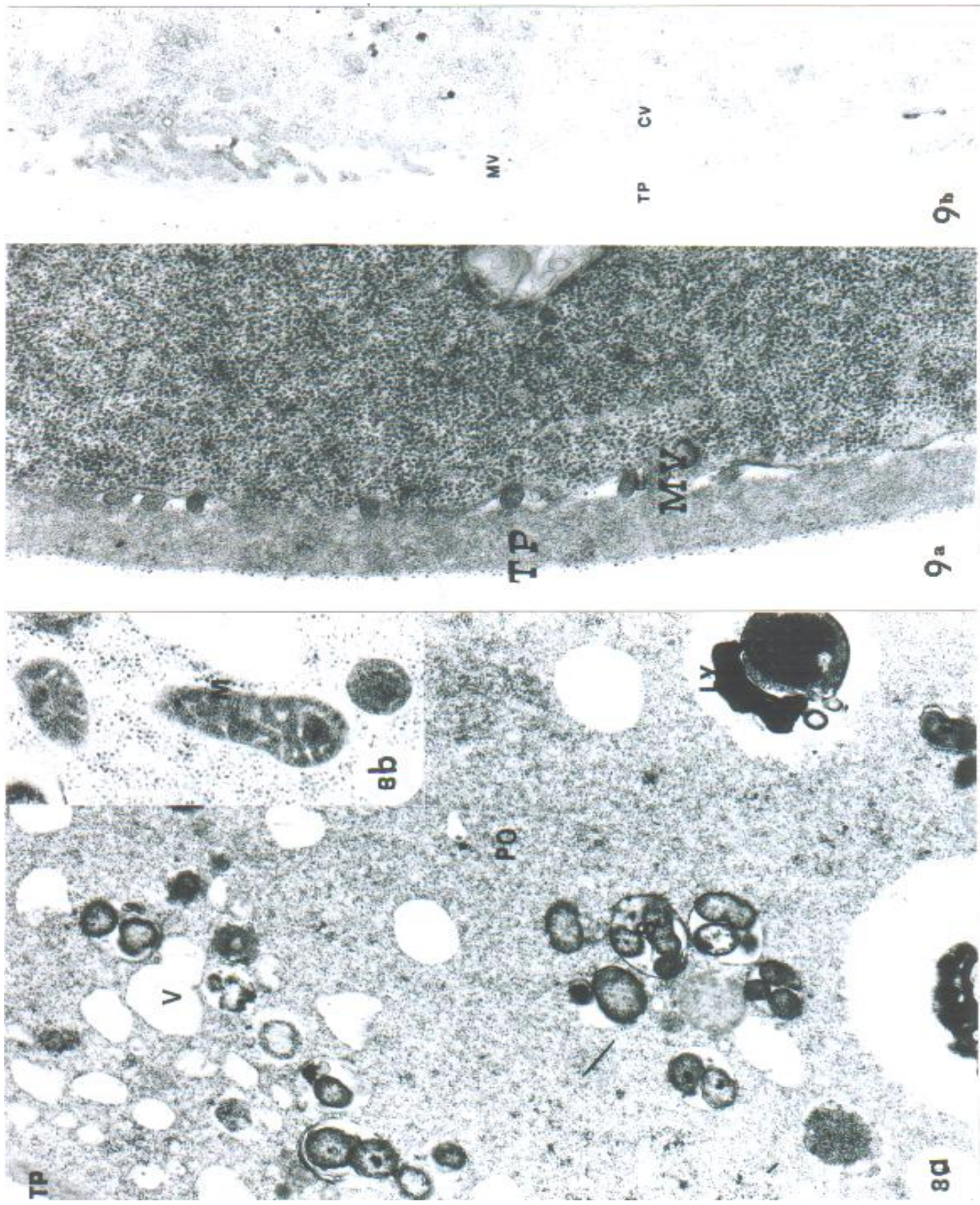

Fig. 8a: Electron micrograph of a part of a previtellogenic oocyte (PO) of unfed A. persicus. LY, lysosomes; S, rickettsia-like microorganisms; TP, tunica propria; V, vacuole (x $16525)$.

Fig. 8b : As in Fig. 8a but higher magnification showing mitochondria (M) (x 42750).

Fig. 9a : Electron micrograph of a part of a previtellogenic oocyte (PO) of unfed A. persicus showing the structure of the tunica propria (TP). MV, microvilli (x 38750).

Fig. 9b: As in Fig. 9a but directly after feeding showing the development of surface microvilli (MV) . cv, coated vesicles ; TP, tunica propria (x 22250). 


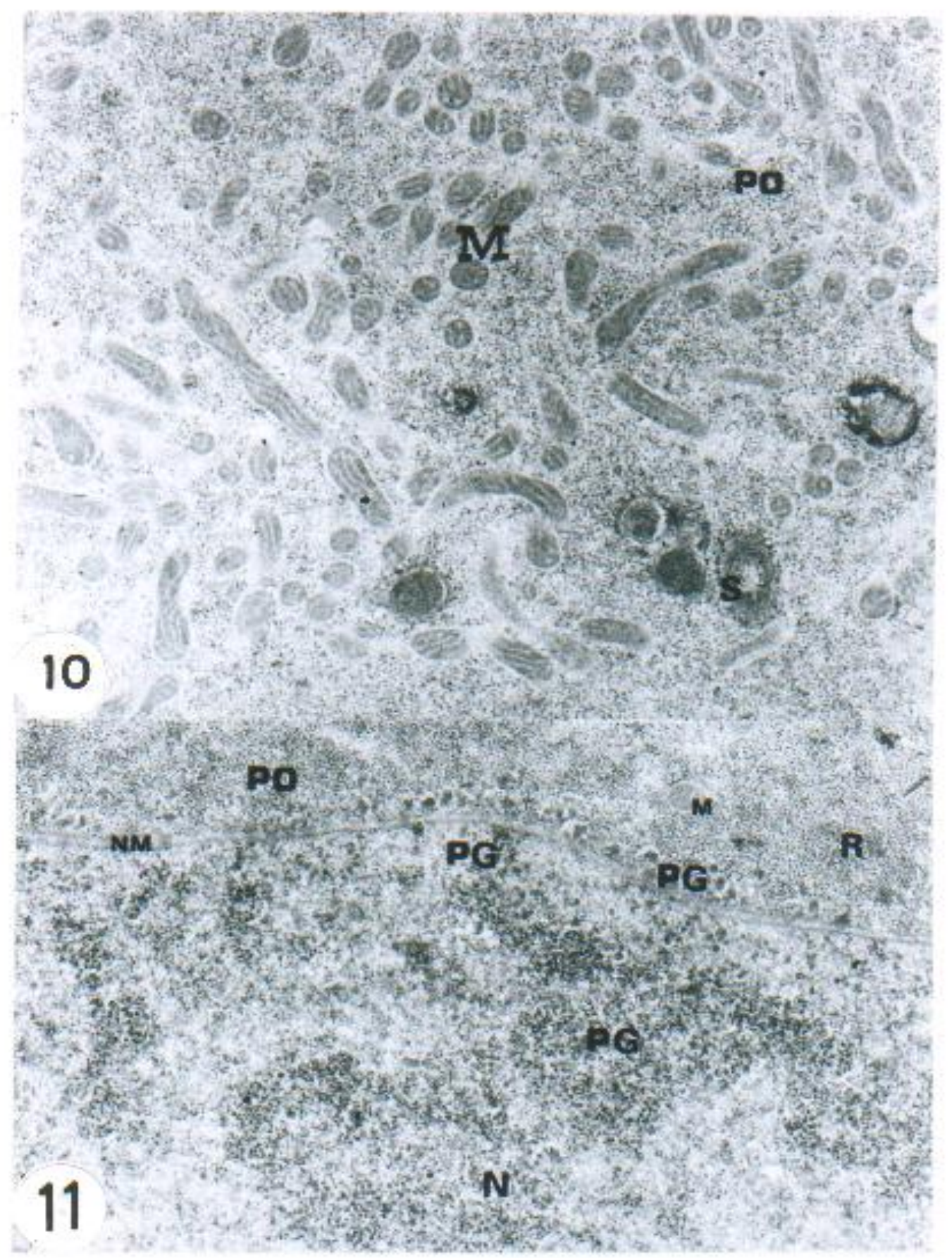

Fig. 10: Electron micrograph of a part of a previtellogenic oocyte (PO) of A. persicus directly after feeding showing multiplication of mitochondria $(\mathrm{M})$. S, rickettsia-like microorganisms ( $\mathrm{x}$ 22250).

Fig. 11: As in Fig.10 but showing the passage of perichromatin granules (PG) from the nucleus (N) toward the cytoplasm through the nuclear membrane (NM). M, mitochondria; R, ribosomes ( $\mathrm{x}$ 22250). 


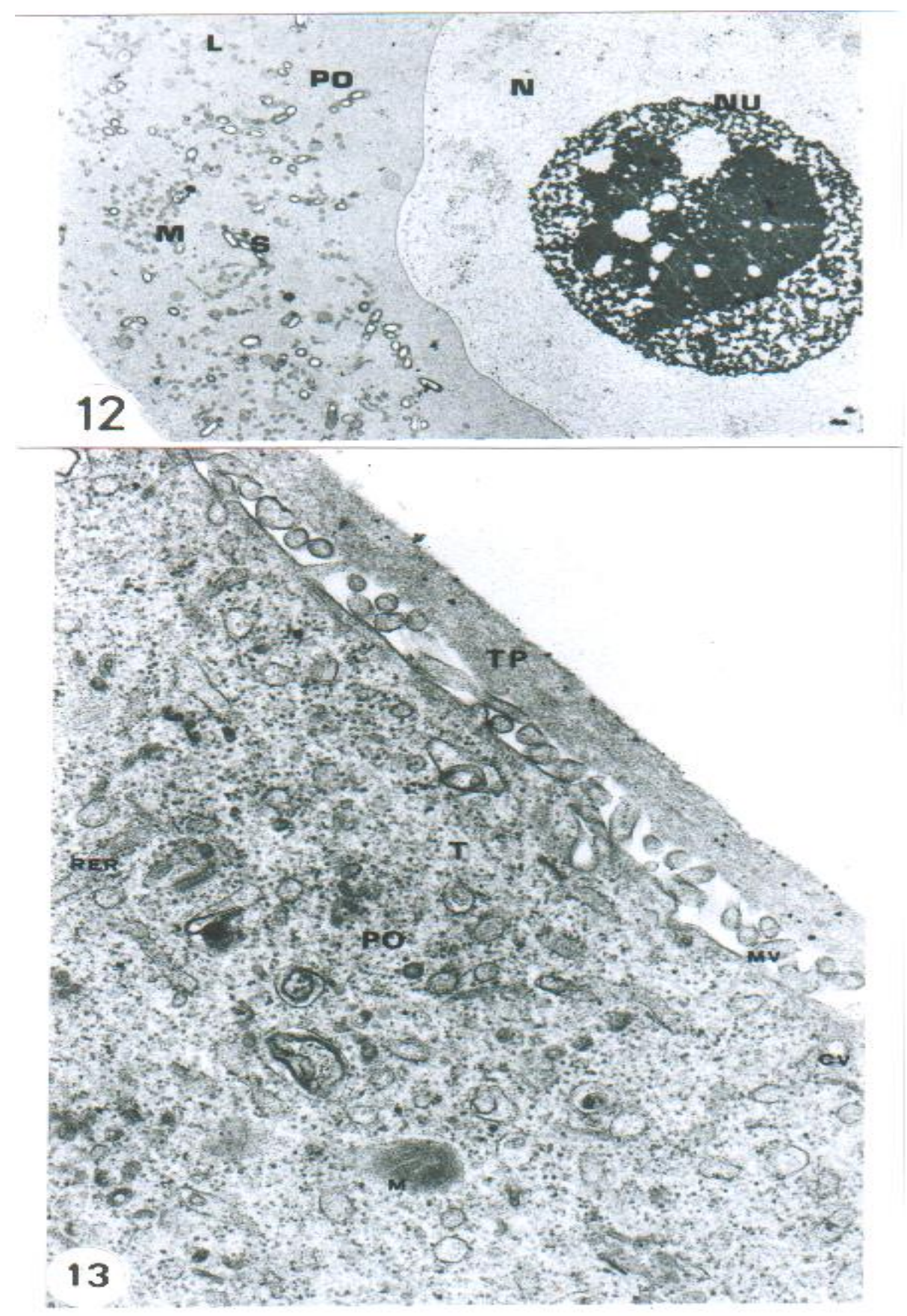

Fig. 12:As in Fig. 11 but 4 days after feeding showing the enlarged nucleus (N) containing fine euchromatin granules in addition to large nucleolus (NU). L, lipid droplets; M, mitochondria; S, rickettsia-like microorganisms (x 3300).

Fig.13: Electron micrograph of a part of a previtellogenic oocyte (PO) of A. persicus 4 days after feeding showing the formation of numerous surface microvilli (MV) underlined with coated vesicles (cv) and microtubules (T). M, mitochondria; RER, rough endoplasmic reticulum; TP, tunica propria (x 38750). 

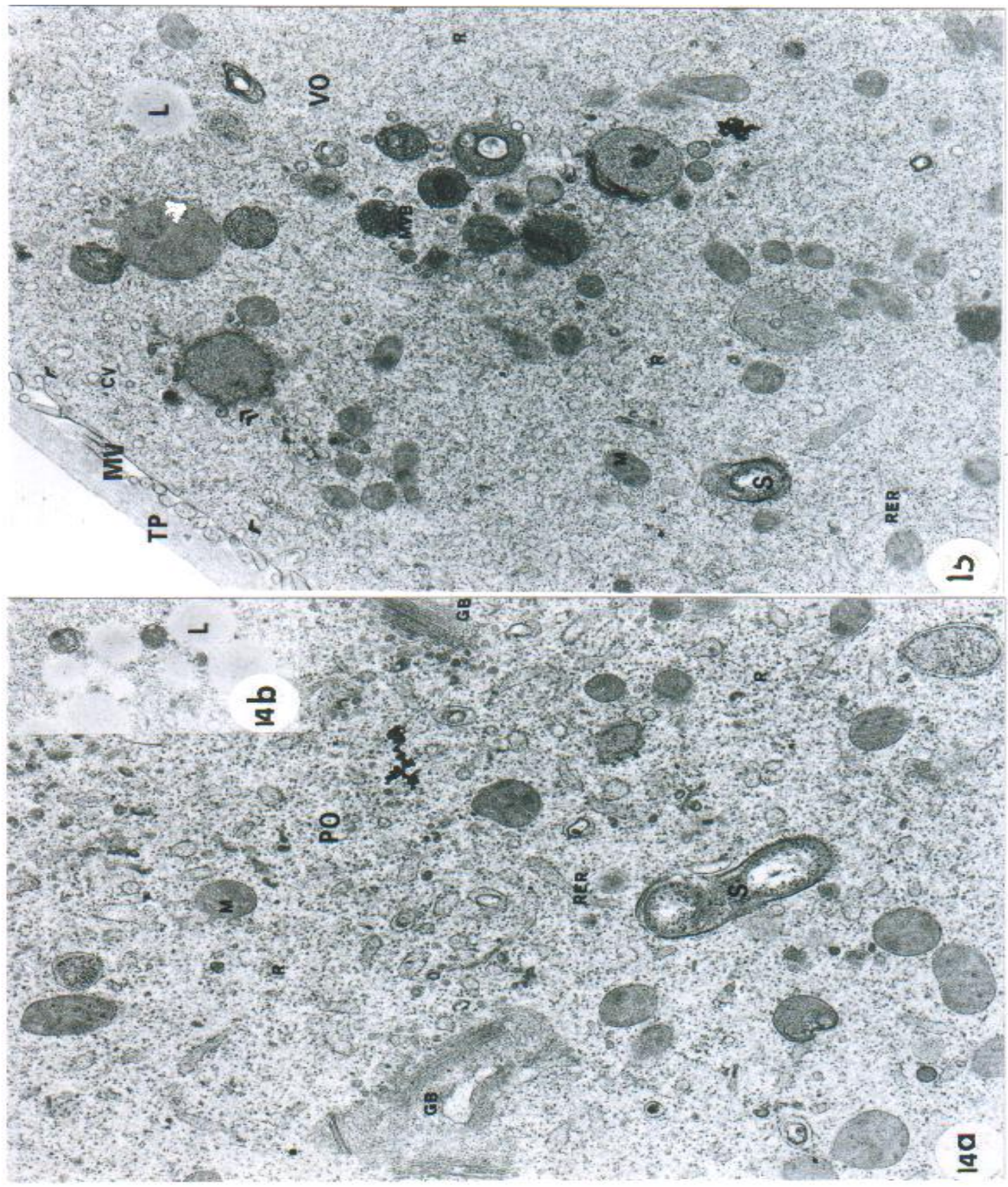

Fig. 14a: Electron micrograph of a part of a previtellogenic oocyte (PO) of A. persicus 4 days after feeding showing development of several groups of Golgi bodies (GB). M, mitochondria; R, ribosomes; RER, rough endoplasmic reticulum; S, rickettsia-like microorganisms (x 28750).

I: Fig.14a but showing lipid droplets (L) (x 22250).

Fig. 15: Electron micrograph of a part of a vitellogenic oocyte (VO) of A. persicus 4 days after feeding showing formation of multivesiculate bodies (MVB). cv, coated vesicles; L, lipid droplets; M, mitochondria; MV, microvilli; R, ribosomes; RER, rough endoplasmic reticulum; S, rickettsia like microorganisms; TP, tunica propria; single arrowheads, micropinocytotic pits; double arrowheads, fusion of coated vesicles to multivesiculate body (x 22250). 


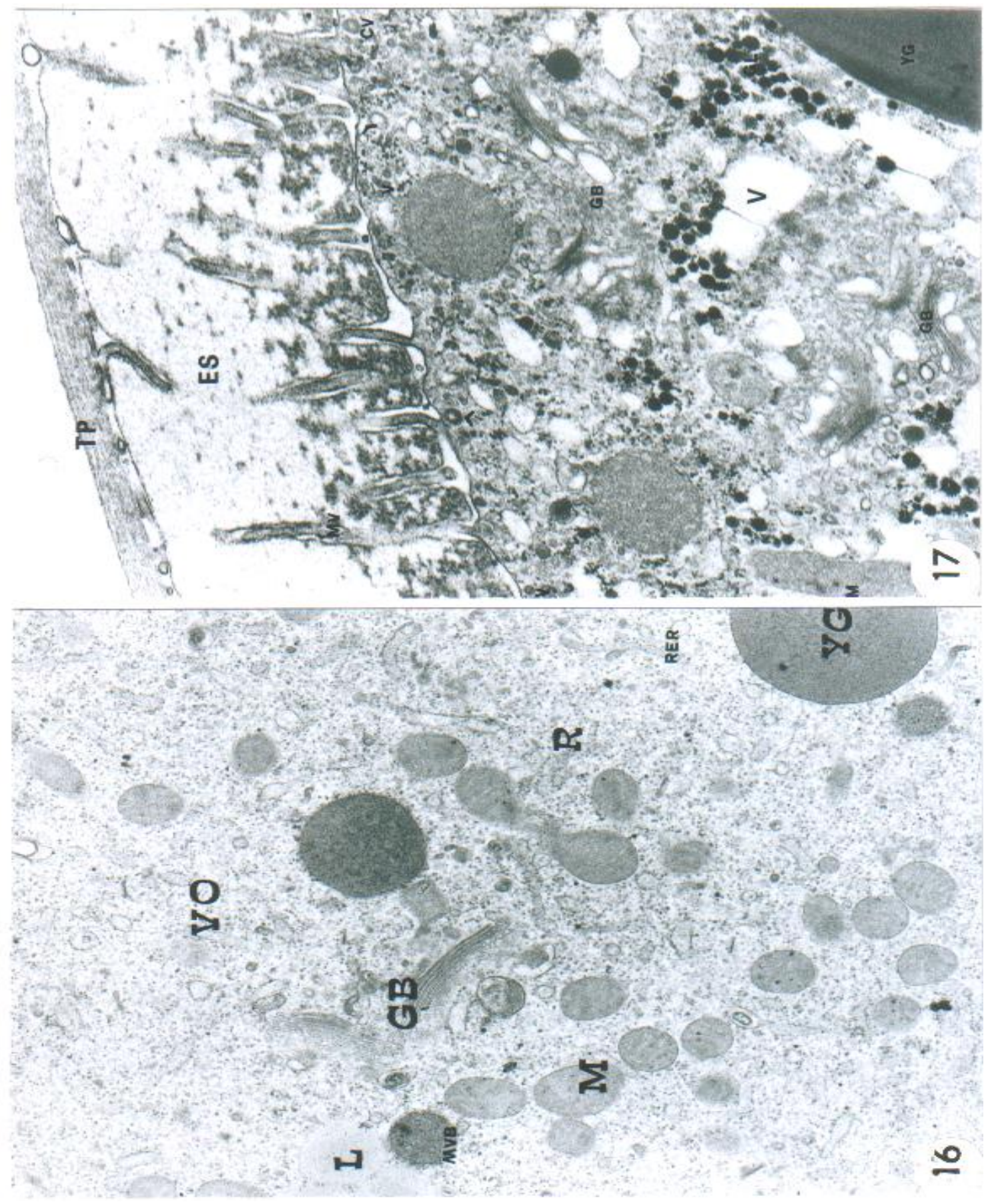

Fig. 16: Electron micrograph of a part of a vitellogenic oocyte (VO) of A. persicus 4 days after feeding showing fully formed yolk granules (YG). GB, Golgi bodies; L, lipid droplets; M, mitochondria; MVB, multivesiculate body; R, ribosomes; RER, rough endoplasmic reticulum (x 28750).

Fig. 17: Electron micrograph of a part of a vitellogenic oocyte (VO) of A. persicus 6 days after feeding showing formation of egg shell (ES) and inclusion of numerous Golgi bodies (GB). cv, coated vesicles; M, mitochondria; MV, microvilli; TP, tunica propria; V, vacuole; v, small vesicles; arrowheads, micropinocytotic pits (x 28750). 

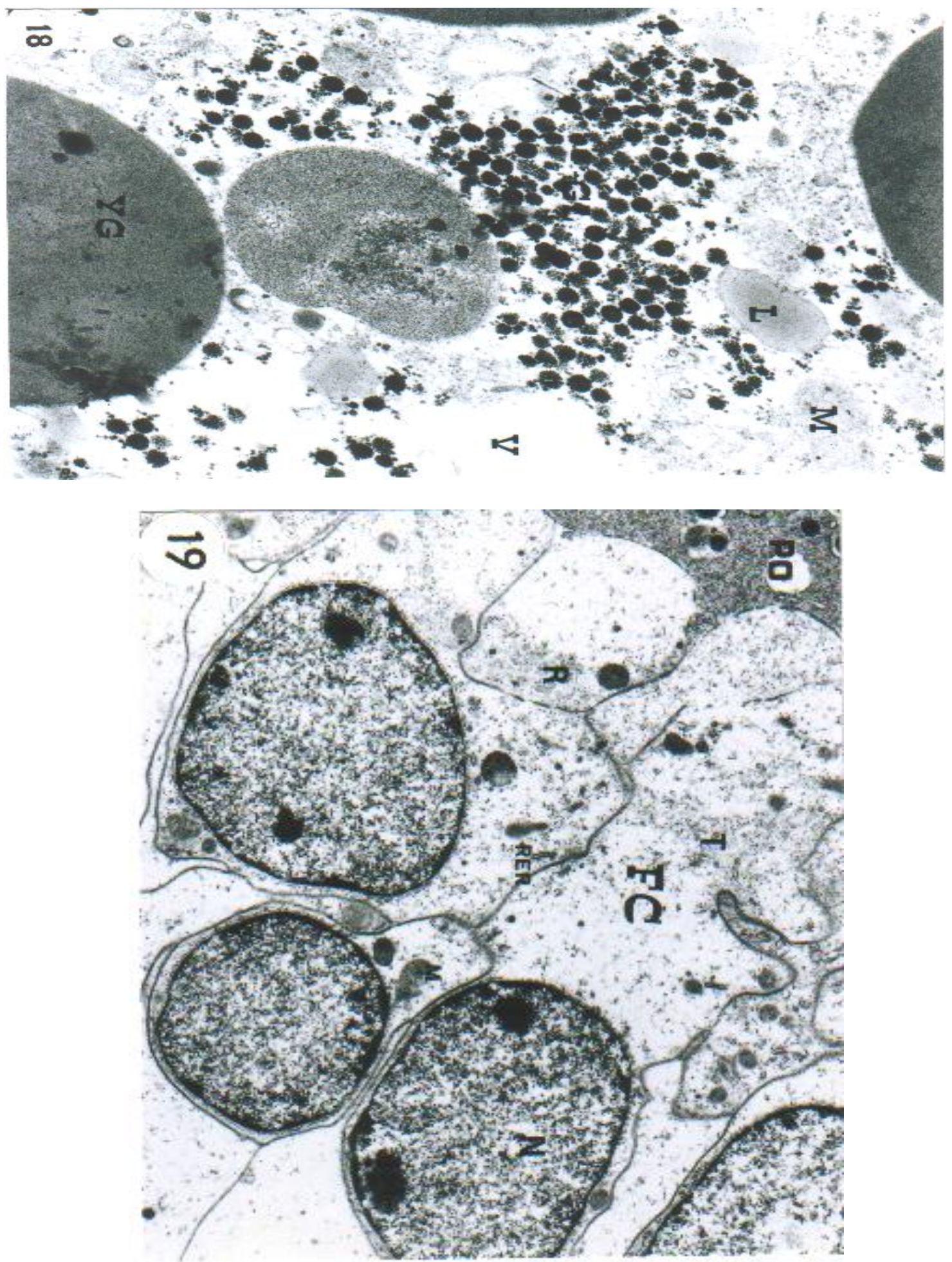

Fig. 18: Electron micrograph of a part of a vitellogenic oocyte (VO) of A. persicus 6 days after feeding showing narrow cytoplasmic areas occupied with large glycogen particles (GL), vacuoles (V) and lipid droplets (L) between yolk spheres (YG) (x 38750).

Fig. 19: Electron micrograph of funicle cells $(\mathrm{FC})$ and their attachment to the previtellogenic oocyte (PO) of unfed A. persicus. $\mathrm{M}$, mitochondria; N, nucleus; R, ribosomes; RER, rough endoplasmic reticulum; T, microtubules (x 9750). 

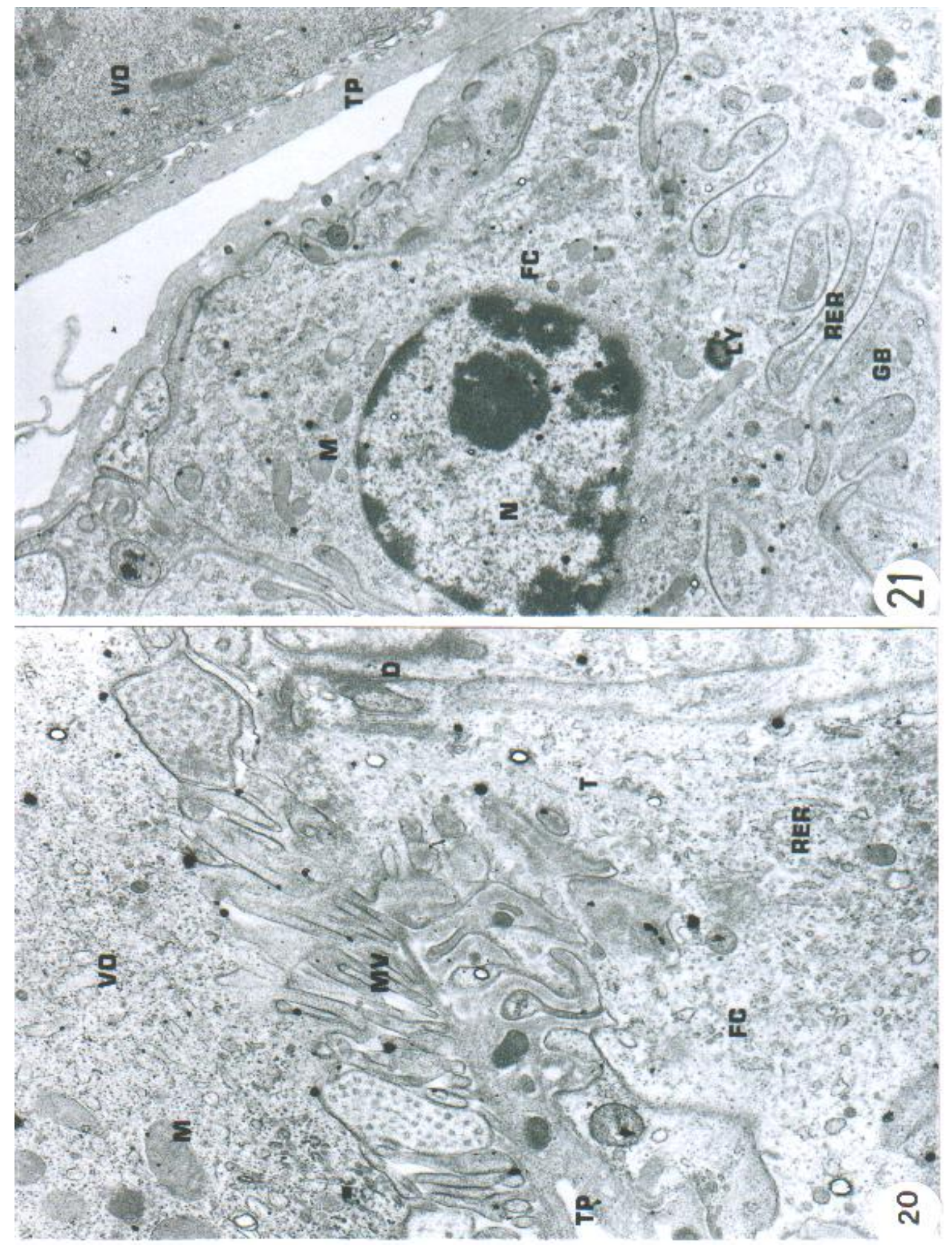

Fig. 20: Electron micrograph of the funicle cell (FC)-vitellogenic oocyte (VO) attachment site of $A$. persicus 4 days after feeding showing desmosomes (D) between funicle cells adjacent to the oocyte in addition to numerous microvilli (MV). M, mitochondria; RER, rough endoplasmic reticulum; T, microtubules; TP, tunica propria (x 28750).

Fig. 21: Higher magnification of a funicle cell (FC) connected to vitellogenic oocyte (VO) of $A$. persicus 4 days after feeding. GB, Golgi bodies; LY, lysosomes; M, mitochondria; N, nucleus; RER, rough endoplasmic reticulum; TP, tunica propria (x 16525). 


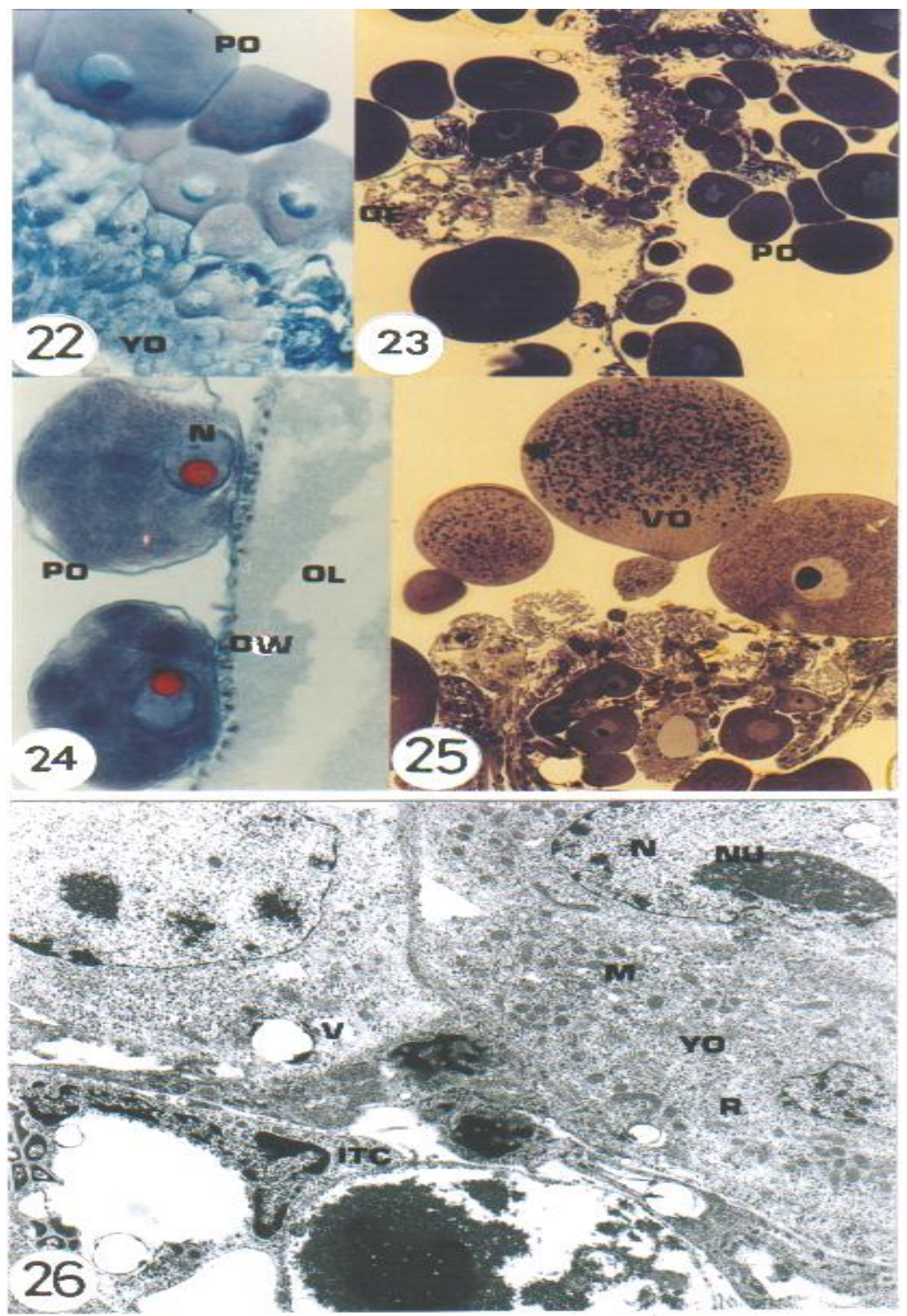

Fig. 22: Transverse section passing through the ovary of $A$. persicus directly after feeding on an ivermectin treated host showing the accumulation of young (YO) and previtellogenic (PO) oocytes (MT stain, x 312.5).

Fig.23: Semithin section of the ovary of A. persicus directly after feeding on an ivermectin treated host showing the damage inthe ovarian epithelium (OE) (MB stain, x 200).

Fig. 24: As in Fig. 22 but 6 days after feeding showing the ovarian lumen (OL) filled with a fluid and the ovarian wall (OW) stretched carrying previtellogenic oocytes (PO) (MT stain, x 312.5).

Fig. 25: As in Fig. 23 but 6 days after feeding showing the appearance of small yolk granules (YG) in few vitellogenic oocytes (VO) (MB stain, x 200).Fig. 61: Transverse section passing through the ovary of $A$. persicus directly after feeding on an ivermectin treated host. PO, previtellogenic oocyte (PAS stain counterstained with Hx stain, x 200).

Fig. 26: Electron micrograph of young oocytes (YO) and interstitial cells (ITC) of A. persicus directly after feeding on an ivermectin treated host. M, mitochondria; N, nucleus ; NU, nucleolus ; R, ribosomes; V, vacuole (x 9750). 


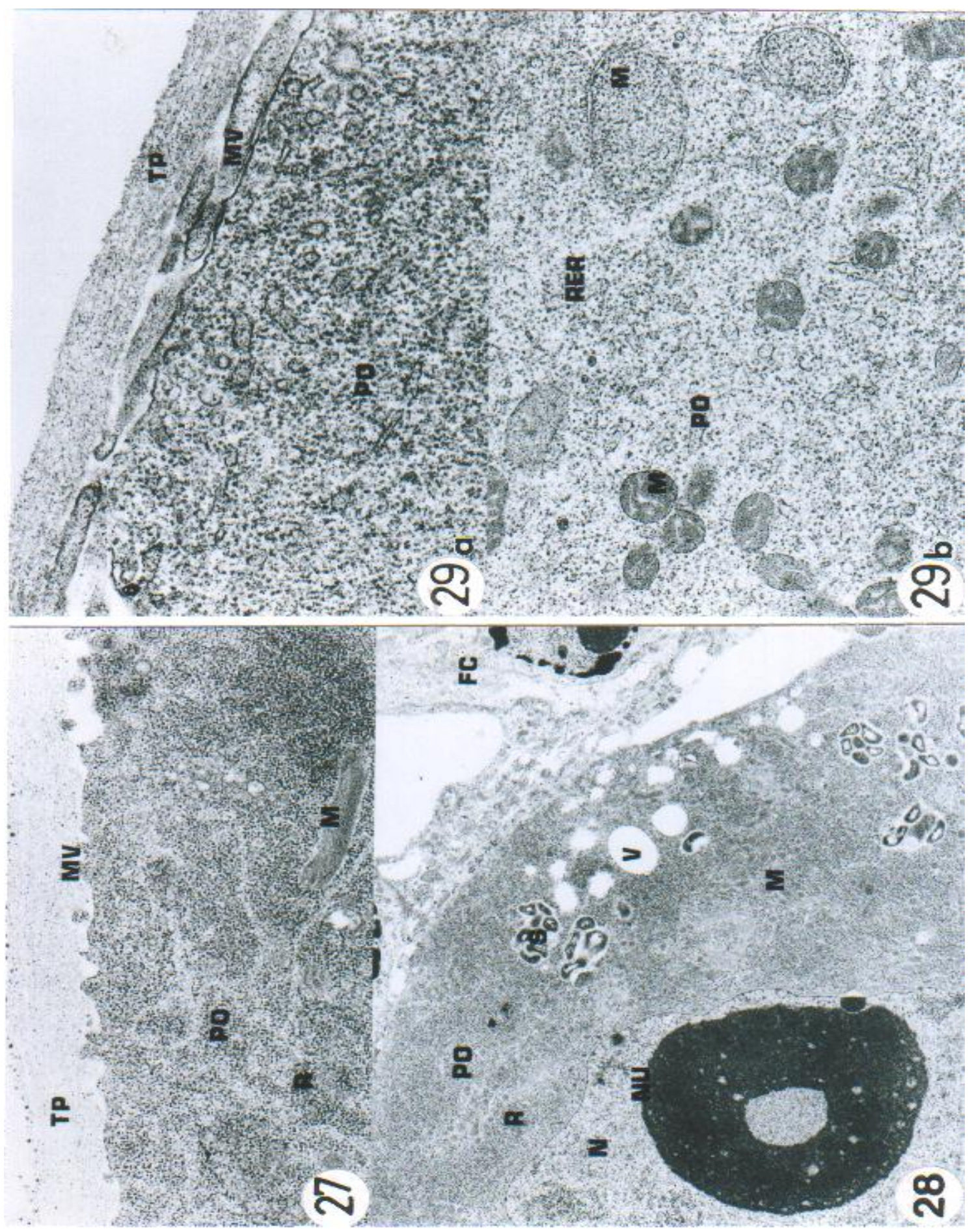

Fig.27: Electron micrograph of a part of a previtellogenic oocyte (PO) of A. persicus directly after feeding on an ivermectin treated host. M, mitochondria; MV, microvilli; R, ribosomes; TP, tunica propria (x 28750).

Fig.28: As in Fig. 27 but showing vacuolation (V) near the oocyte (PO)-funicle cells (FC) attachment site. M, mitochondria; N, nucleus; NU, nucleolus; R, ribosomes; S, rickettsia-like microorganisms (x 9750).

Fig. 29a: Electron micrograph of a part of a previtellogenic oocyte (PO) of A. persicus 6 days after feeding on an ivermectin treated host showing fewer microvilli (MV). TP, tunica propria (x 52500).

Fig. 29b: As in Fig. 29a but showing mitochondrial (M) degeneration. RER, rough endoplasmic reticulum (x 38750). 


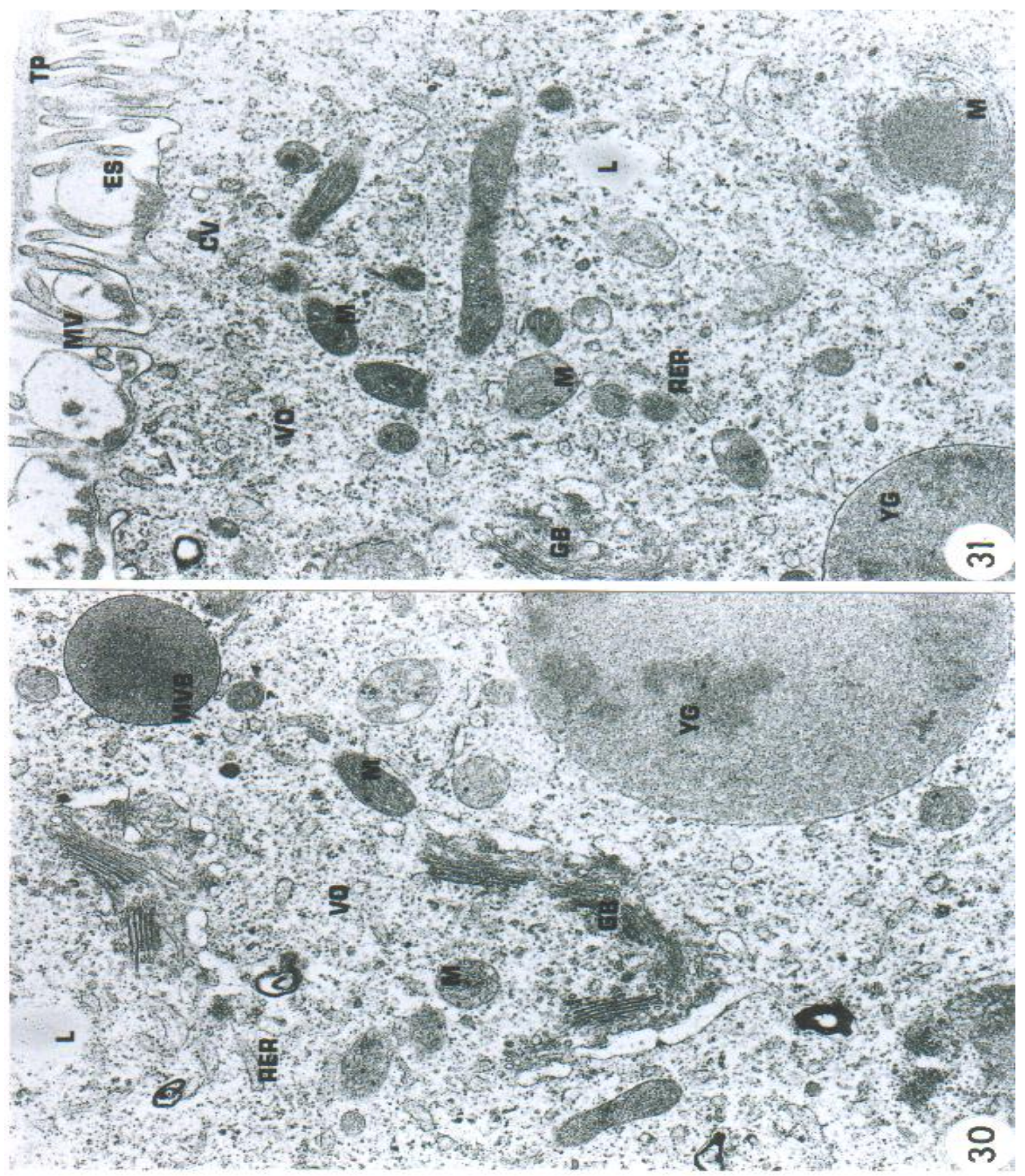

Fig. 30: Electron micrograph of a part of a vitellogenic oocyte (VO) of A. persicus 6 days after feeding on an ivermectin treated host showing formation of multivesiculate bodies (MVB), yolk granules (YG) and several Golgi bodies (GB). L, lipid droplets; M, mitochondria; RER, rough endoplasmic reticulum (x 28750).

Fig. 31: Electron micrograph of a part of a vitellogenic oocyte (VO) of A. persicus 6 days after feeding on an ivermectin treated host showing formation of egg shell (ES) and yolk granules (YG) as well as sharing of degenerated mitochondria (M) and rough endoplasmic reticulum (RER) in yolk formation. cv, coated vesicles; GB, Golgi bodies; L, lipid droplets; MV, microvilli; TP, tunica propria (x 28750). 

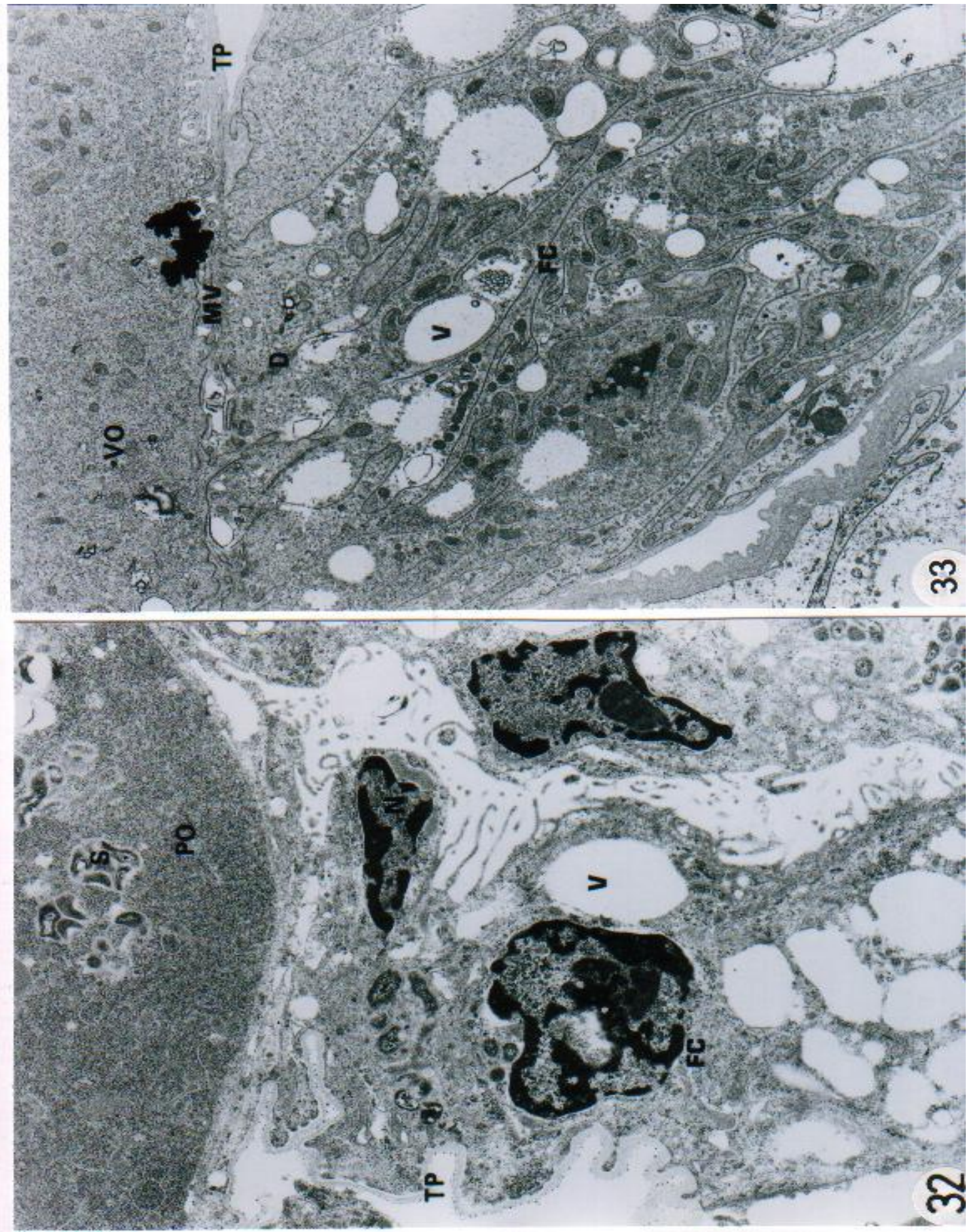

Fig.32: Electron micrograph of the funicle cells (FC) attached to previtellogenic oocyte (PO) of $A$. persicus directly after feeding on an ivermectin treated host. $\mathrm{N}$, nucleus; S, rickettsia-like microorganisms; TP, tunica propria; V, vacuole (x 13000).

Fig. 33: Electron micrograph of the funicle cells (FC) attached to vitellogenic oocyte (VO) of $A$. persicus 6 days after feeding on an ivermectin treated host. D, desmosomes; MV, microvilli; TP, tunica propria; V, vacuole (x 9750). 


\section{Discussion}

\section{General structure:}

In the present study, the position and structure of the single, transverse ovary in $A$. persicus lying in the posterior half of the body, with ova at different developmental stages protr uding onto its surface is identical to those described in other argasids (Balashov, 1972; El Shoura, 1975; El Shoura, 1988) .

The histological and ultrastruc tural examination of $A$. persicus, revealed that the ovarian wall consists of an inner epithelial layer enclosing a narrow central lumen and an outer delicate connective tissue sheath or tunica propria similar to that described in other ticks (Roshdy , 1967). The ovary before feeding contains ova in early stages of development. Tube-like passageway termed pedicels, connect the epithelium and the ovarian lumen with oocytes protruding onto the ovary surface . However, following a blood meal, the oocytes in A. persicus as in other argasids and ixodids grow at various rates and the previtellogenic and vitellogenic stages of primary oocytes together with oogonia are thus observed in the same ovary. At any rate, a physiological trigger apparently is necessary to stimulate vitellogenesis (Khalil, 1969). Feeding and engorge ment apparently provide a stimulus mediated via the central nerve mass that initiates mitotic activity (Brinton and Oliver, 1971). The fact that oocytes of different developmental stages can be encountered at any time ensures the prolongation of vitellogenesis and hence oviposition period. This prolongation may have definite advantages for efficient production of egg batches allowing enough time for handling of eggs during water proofing by Gene's organ and permitting extracellular source of yolk material to synthesize and export the precursors of yolk.

The general course of oocyte development and growth is also similar in the present studied tick to that described earlier in argasids (Roshdy, 1967; Khalil, 1969; Brinton and Oliver,1971; El Shoura et al.,1989). Balashov (1972) described A. persicus oogenesis in detail in five stages. Stage one is a period of "small growth" of primary oocytes and is always present in the ovary. Stage two is the period of great nuclear and cytoplasmic growth and ends with the appearance of the first yolk granules in the cytoplasm. Stages three and four are characterized by the appearance of yolk granules and end with ovulation. Stage five begins with mature eggs "coming into the lumen of the ovary".

In the present study, young oocytes greatly resemble stage I of Balashov's classification (1972) which resulted from oogonial division and during which the oocyte nucleus and cytoplasm increase only slightly (Diehl et al., 1982). The fine structure of primary oocytes and interstitial cells of unfed A. persicus in the present study is basically similar to that in other ticks viz in unfed (Aeschlimann and Hecker, 1970; Raikhel, 1978; Balashov, 1983 El Shoura et al., 1989). Primary oocytes of unfed $A$. persicus are found to demonstrate few small mitochondria and rough endoplasmic reticulum. Following feeding, mitochondria become numerous and fill most of the oocyte cytoplasm. The nucleus becomes large and is filled with fine granules of euchromatin, masses of heterochromatin and large dense nucleolus.

Previtellogenic oocytes observed in the present study correspond to stage II of Balashov's classification in which the cytoplasm greatly increases and 
lasts till the appearance of the first yolk granules. The ultrastructure of previte llogenic oocytes, which corresponds to stage II of Balashov's classification (1972), reveals a gradual increase in mitochondria and surface microvilli. Brinton and Oliver (1971) revealed that morphogenic changes of the mitocho ndria exhibit their involvement in the production of membrane-limited multi vesiculate bodies. Rough endoplasmic reticulum and Golgi bodies are similarly developed and increased when compared to the unfed condition and microvilli become longer and more numerous. Surface microvilli in the growing oocytes are thought to facilitate micropinocytosis of nutrient material from the haemolymph (Diehl et al., 1982). Towards the end of the great cytoplasmic growth phase, numerous lipid droplets are observed. Lipids observed between yolk granules in the vitellogenic phases of ticks were previously documented in $A$. arboreus (El-Shoura et al., 1989). The nucleus of the previtellogenic oocytes exhibits a notable increase within the few days following feeding. Such increase was also reported in A. arboreus (El-Shoura et al., 1989). Also, aggregates of perichromatin granules are observed beneath the nuclear membrane and pass through its pores to the cytoplasm. These granules were histochemically demonstrated as ribonucleoproteins and considered to be ribosomal precursors (Diehl et al., 1982).

Vitellogenic oocytes characterized by the formation of yolk droplets are similar to stages III and IV of Balashov's classification. The vitello genic phases of oocyte growth begin with the appearance of the first yolk granules and ends with ovulation (Diehl et al., 1982). They are similar to stages III and IV of Balashov classification. The yolk formation in tick oocytes may originate from both intracellular and extracellular sources ( Diehlet al., 1982; Balashov, 1983; El-Shoura et al., 1989). The intracellular source mainly depe nds on the activities of the internal organelles as rough endoplasmic reticu lum, Golgi bodies and mitochondria. In the present study, they are well developed and become more numerous within the few days following feeding. The fusion of small vesicles derived from Golgi bodies and rough endoplasmic reticulum in addition to mitochondria, ribosomes and perichr omatin granules, emitted from the nucleus, into multivesicular bodies (yolk granule precursor) supportsthe intraoocytic source of yolk formation. The multivesicular bodies are mainly formed of proteins (Brinton and Oliver, 1971; Balashov, 1983). Similar involv ement of mitochondria, dictyosomal vesicles, nuclear emissions and ribos omes in the formation of primary yolk bodies have been observed in several insects and arachnids (Brinton and Oliver, 1971).The extraoocytic source of yolk is evident by the form ation of surface microvilli underlined with several micropinocytotic pits and vesicles. These vesicles subsequently appear to fuse with each other and with multivesicular bodies and transformed into large homogeneous yolk spheres through repeated fusions and dissolution of vesicle membranes. Similar observ ations were obtained in $R$. bursa (Hecker and Aeschlimann, 1970), D. andersoni (Brinton and Oliver, 1971), Amb. hebraeum (Diehl et al., 1982) and A. arboreus (El-Shoura et al., 1989). In the present study, large rosette-like glycogen deposits and lipid droplets accumulate in the oocyte cytoplasm between yolk granules. Similar results were obtained in previous ultrastructural investigations (Hecker and Aeschl imann, 1970; El Shoura et al., 1989). 
Ultrastructural examination in the present study reveals that the funicle cells carrying oocytes are irregular in shape, fastened to each other by several desmosomes and collectively coated with tunica propria. They contain large nuclei, few cisternace of rough endoplasmic reticulum, small mitoch ondria and microtubules. Microtubules increase during the process of vitello genesis particularly near the oocytefunicle cells attachment site. This is thought to enhance the mechanical role of such cells as suggested by Diehl et al. (1982). Desmosomal junctions connecting these cells also supported this function.

Deposition of egg-shell in the present study is found to begin slightly after the start of yolk formation. This greatly coincides with results obtained by Diehl et al. (1982) on Amb. hebraeum who recorded its beginning during Balashov's stage III of oocyte development and completion during stage IV (stages of yolk deposition). Egg-shell is mainly formed from vesicles, derived from Golgi bodies and endoplasmic reticulum, passes to the extracellular space below the tunica propria and is polymerized around microvilli. Participation of Golgi bodies in shell formation was previously suggested in $H$. asiaticum (Raikhel, 1978). The pattern of shell formation in the present study coincides with that described in Amb. hebraeum (Diehl et al., 1982), H. asiaticum (Balashov, 1983) and A. arboreus (El Shoura et al., 1989).

\section{Effect of ivermectin:}

In the present study on $A$. persicus, the single subcutaneous injection of the host by ivermectin at the dose rate $400 \mathrm{ug} / \mathrm{kg}$ affected growth and development of the oocytes following feeding, where the size of ova and their nuclei were comparatively smaller in the treated ones. Vitellogenesis was not inhibited totally, however the dose affected yolk formation causing disrupted vitellogenesis, accompanied by a noticeable depletion and ununi formity of the formed yolk particles and the absence of glycogen during the examined period.

Ivermectin was also found to induce the presence of a fluid in the ovarian lumen which caused its dilatation and hence the ovarian wall appears considerably stretched when compared with the untreated group.

Ultrastructural observation revea led a notable decrease in microvilli, micropinocytotic vesicles and perich romatin granules that traverse the nuclear membrane. Vacuolation was observed in parts of the cytoplasm as well as degeneration of mitochondria and rough endoplasmic reticulum.

However, ivermectin did not completely prevent the formation of egg shell where its thickness measured about half of the untreated one. It also caused the decrease in the number of coated vesicles that share in egg-shell formation.

Data concerning the histopatho logical effect of ivermectin on ticks are rare, since most workers concentrated on its systematic efficacy and on ticks biological response to various levels of the drug (Drummond et al., 1981; Lancaster et al., 1982; Campbell et al., 1983; Drummond, 1985). Drummond et al. (1981) mentioned that ivermectin do not block vitellogenesis specifically. First they report that ivermectin does not affect the appearance of gonadal tissues in small ticks. Secondly, when a few small females were transferred from an ivermectin treated to a control calf, they reattached, engorged and laid small -to moderate- sized egg masses that had a reduced hatch. Kaufman et al. (1986) studied the effect of ivermectin 
on feeding, salivary gland fluid secretion and fecundity in some ixodid ticks. When injected into engorged ticks, the drug increased oviposition latency and reduced fecundity. On the other hand, ivermectin was reported to reduce the rate of vitellogenesis and follicle development, in fire ants (Lofgren and Williams, 1982), produ cing marked histopathological effects in the ovaries (Glancey et al., 1982). Similar effects are also described in the mosquito Aedes aegypti (Mahmood et al., 1991) after the ingestion of blood containing the drug. The authors described histological changes occur ring as degeneration of primary follicles, formation of ovarian dilatations, significant reduction of the rate of vitellogenesis and follicle development, expressed by little or no yolk deposition. Similar histopatho logical effects were reported in the nematodesMolinema dessetae (Duarte et al., 1994) and Capillaria hepatica (El-Nassery et al., 1996).

Ultrastructural changes including degeneration, vacuolization of the cytoplasm and condensation of nuclei were reported in muscle cells as well as smoothening, ulcer formation and stretching in some parts of the cuticle due to ivermectin treatment in $O$. volvulus (Wildenburg et al., 1994), C. hepatica (El-Gebaly et al., 1996) and Trichinella spiralis (El-Azzouni, 1997). Moreover Perez et al.(2001)stated that the cestoeidal effect of ivermectin on the tapeworm, Echinococcus granul osus is through its effect on the tegument and causing a state of depolarization followed by rostellar disorganization, rigid paralysis and, eventually loss of viability. El-Gebaly $e t$ al. (1996) and El-Nassery et al. (1996) demonstrated shrinkage and deform ation in the egg-shell of $C$. hepatica together with some irregularities and longitudinal grooves as well as fragmentation of some surface pillars. Ivermectin exerted its therapeutic effect by action on ligandgated membrane ion-channels partic ularly glutamate gated channels which have so far been found only in invertebrates (Martin et al., 1998;Perez et al., 2001). Ivermectin increased inward current through membranes of Xenopus laevis oocytes. Such currents were activated in presence of glutamate and desensitized in the continued presence of glutamate (Arena et al., 1992). The latter authors proposed that the glutamate-sensitive chloride current and the avermectin-sensitive chloride current were mediated via the same channel. Ivermectin was also capable of binding to the membrane transporter-P-glycoprotein in mouse and human (Schinkel et al., 1995; Brown, 1998) and to P-glycoprotein in nematodes (Smith and Prichard,2002). The lipophilic nature of ivermectin was previously observed by its ability to unite with the lipid phase of muscle membranes of Ascaris suum (Martin and Kusel, 1992).

Nothing is known about the sites or mechanism of action of the avermectins in ticks. In the nematode, Ascaris, avermectin causes paralysis by blocking transmission between interne urons and excitatory motoneurons in the ventral nerve cord; while the $\gamma$-aminob utyric acid (GABA)-antagonist, picrot oxin, reverses avermectin-induced blockade (Kass et al., 1980). Other studies indicate that avermectins stimulate GABA systems in general: (1) they stimulate GABA-mediated chloride conductance in a number of preparations (Mellin et al., 1983); (2) they bind avidly to dog brain synaptosomes (Pong and Wang, 1980); and (3) they stimulate release of GABA from rat brain synaptosomes (Pong et 
al., 1980). Avermectin also has effects on benzodiazepine receptors (Supavilai and Karobath, 1981), and on presynaptic GABA receptors (Pong and Wang, 1979). The fact that avermectin induces immobilization in helminths as well, suggests that avermectins cause their anti-parasite effect by interacting with a putative GABA pathway in helminths.

In ticks, it seems probable that an insect-like juvenile hormone is used as a gonadotropic hormone to regulate vitellogen production and other aspects of oogenesis (Diehl et al., 1982). Experiments have also implicated the synganglion as the seat of an endocrine mechanism regulating oogenesis (Shanbaky and Khalil, 1975). Gabbay and Warburg (1976) suggested that a neurosecretory product is involved in the first step of an endocrine mechanism regulating the digestion or mobilization of blood-meal proteins, the initiation of vitellogenin production and its release into the haemolymph and/or its incorportaion into developing oocytes. Data from the present study suggests a partial blockage of the release of vitellogenetic hormone as indicated by disrupted synthesis and uptake of yolk protein in the developing oocytes. However, still more work is needed to assess the exact titre of vitellin in the ovary in an attempt to fully understand ivermectin exact mode of action.

\section{References}

1. Aeschlimann, $\mathbf{A}$ and Hecker, $\mathbf{H}$. (1970): Presence de membranes annu lees dans les ovocytes d, Ornithodoros moubata Murray (Ixodoidea: Argasidae). Acta Trop., 27:268-70.

2. Arena, J. P., Liu, K. K., Paress, P. S., Schaeffer, J. M. and Cully, D. F. (1992): Expression of a glutamateactivated chloride current in Xenopus oocytes injected with Caenorhabditis elegans RNA: evidence for modulation by avermectin. Brain Res. Mol. Brain Res., 15(3-4): 339-348.

3. Balashov, Yu. S. (1972): Bloodsucking ticks (Ixodoidea)-Vectors of diseases of man and animals. Nauka, Leningrad. English Translation, Misc. Publ. Ent. Soc. Am., 8: 161-376.

4. Balashov, Yu. S. (1983): An atlas of ixodid tick ultrastructure. (In Russian). Zool. Instit., USSR Acad. Sci., Nauka, Leningrad. English Translation, Special Publ. Ent. Soc. Am.

5. Brinton, L. P. and Oliver, J. H. (1971): Fine structure of oogonial and oocyte development in Dermacentor andersoni Stiles (Acari: Ixodidae). J. Parasitol., 57(4): 720-747.

6. Brown, K. R. (1998): Changes in the use profile of Mectizan: 1987-1997. Ann. Trop. Med. Parasitol., 92(Suppl. 1): S61-4.

7. Campbell, W. C. (1989): Ivermectin and abamectin. Springer-Verlag New York Inc., USA, pp. 363.

8. Campbell, W. C., Fisher, M. H., Stapley, E. O, Albers-Schonberg and Jacob, T. A. (1983): Ivermectin: a potent new antiparasitic agent. Science, 221: 823-828.

9. Deply, L. and Kaweh, M. (1937): Transmission de Bacillus anthracis à l'homme par Argas persicus Oken 1818. Rev. Path. Comp. Hyg. Gén, 37: 1229-1234.

10. Diehl, P. A., Aeschlimann, A. and Obenchain, F. D. (1982): Tick reproduction: oogenesis and ovipo sition. In: Obenchain, F. D. and Galun, R.(eds.). Physiology of ticks. Pergamon Press, Oxford, pp. 277-350.

11. Drummond, R. O. (1985): Effectiveness of ivermectin for control of arthropod pests of livestock. Southwest. Entomol., Suppl. 7: 34-42.

12. Drummond, R. O., Whetstone, T. M and Miller, J. A. (1981): Control of tick systemically with Merck MK-933, an avermectin. J. Econ. Entomol., 74: 432-436.

13. Duarte, Z., Gantier, J. C. and Gayral, P. (1994): Macrofilaricidal activity of albendazol-ivermectin 
combination: Histopathological evaluation of adult Molinema dessetae. Trop. Med. Parasitol., 45: 209-213.

14. Einstein. R., Jones, R. S., Knifton, A. and Starmer, G. A. (1994): Principles of veterinary therapeutics. Longman Group UK Lt., 591 pp.

15. El-Azzouni, M. Z. O. (1997): Effect of ivermectin on experimental trichinosis. J. Egypt. Soc. Parasitol., 27(2): 331340.

16. El-Gebaly, M. W., El-Nassery, S. F., El-Azzouni, M. Z., Hammouda, N. A. and Allam, S. R. (1996): Effect of mebendazole and ivermectin in experi mental hepatic capillariasis: Parasito logical, scanning electron microscopy and immunological studies. J. Egypt. Soc. Parasit., 26(1): 261-274.

17. El-Nassery, S. F., El-Gebaly, M. W., El-Azzouni, M. Z., Hammouda, N. A., El-Shenawie, S. and Allam, S. R. (1996): Effect of mebendazole and ivermectin in experimental hepatic capillariasis B: Histopathological and ultrastructural studies. J. Egypt. Soc. Parasitol., 26(2): 315-326.

18. El-Shoura, S. M. (1975): Biological and morphological studies on the tick Ornithodoros (Pavlovskyella) erraticus. M.Sc. Thesis, Ain Shams Univ., Cairo, Egypt, 131 pp.

19. El-Shoura, S. M. (1988): Fine structure of the vagina, accessory glands, uterus, oviducts and Gene's organ in the unfed tick, Ornithodoros (Pavlovskyella) erraticus (Ixodoidea: Argasidae). Exp. Appl. Acarol., 4(2): 95-108.

20. El-Shoura, S. M., Banaja, A. A. and Roshdy, M. A. (1989): Fine structure of the developing oocytes in adult Argas (Persicargas) arboreus (Ixodoidea: Argasidae). Exp. Appl. Acarol., 6: 143-156.

21. Gabbay,S. and Warburg ,M.R. (1976): Neurosecretory activity as related to feeding, mating and oogenesis in the female cave tick, Ornithodoros ttholozani. .Insect Physiol., 22: 1291-1301.
22. Genchi, C. (1992): Arthropoda as zoonoses and their implications. Vet. Parasitol., 44(1-2): 21-33.

23. Glancey, B. M., Lofgren, C. S. and Williams, D. F. (1982): Avermectin $\mathrm{B}_{1} \mathrm{a}$ : Effects on the ovaries of red imported fire ant queens (Hymenoptera: Formicidae). J. Med. Entomol., 19: 743-747.

24. Gothe, R., Kunze, K. and Hoogstraal, H. (1979): The mechanisms of pathog enicity in the tick paralyses. J. Med. Entomol., 16: 357-369.

25. Hecker, H. and Aeschlimann, A.(1970). Ultrastrukturelle aspekte der eibilung bei Rhipicephalus bursa (Canestrini and Fanzaga) ( Ixodoidea. Ixodidae).Z. Trop. Parasitol.,

26. Kass, I. S., Wang, C. C., Walrond, J. P. and Stretton, A. O. W. (1980): Avermectin $\mathrm{B}_{1} \mathrm{a}$, a paralyzing anthelm intic that affects interneurons and inhi bitory motoneurons in Ascaris. Proc. Natl. Acad. Sci. USA, 77: 6211-6215.

27. Kaufman, W. R., Ungarian, S. G. and Noga, A. E. (1986): The effect of avermectins on feeding, salivary fluid secretion, and fecundity in some ixodid ticks. Exp. Appl. Acarol., 2: 1-18.

28. Khalil, G. M. (1969): Biochemical and physiological studies of certain ticks (Ixodoidea). Gonad development and gametogenesis in Argas (Persicargas) arboreus Kaiser, Hoogstraal and Kohls (Argasidae). J. Parasitol., 55: 12781297.

29. Lancaster, Jr., J. L., Kilgore, R. L. and Simco, J. S. (1982): Efficacy of low level daily doses of ivermectin in calves against three species of ticks. Southwest. Entomol., 7(2): 116-118.

30. Lofgren, C. S. and Williams, D. F. (1982): Avermectin $B_{1}$ a: highly potent inhibitor of reproduction by queens of the red imported fire ant (Hymenoptera: Formicidae). J. Econ. Entomol., 75: 798-803.

31. Mahmood, F., Walters, L. L., Guzman, H. and Tesh, R. B. (1991): Effect of ivermectin on the ovarian development of Aedes aegypti (Diptera: Culicidae). J. Med. Entomol., 28(5): 701-707. 
32. Martin, R. J. and Kusel, J. R. (1992): On the distribution of a fluorescent ivermectin probe (4" 5,7 dimethylbodipy proprionylivermectin) in Ascaris membranes. Parasitology, 104: 549-555.

33. Martin, R. J., Murray, I., Robertson, A. P., Bjorn, H. and Sangster, N. (1998): Anthelmintics and ionchannels: after a puncture, use a patch. Int. J. Parasitol., 28(6): 849-62.

34. Montasser,A.A.M.( 2000 ):Effect of ivermectin on the tick Argas (persicargas) persicus (Oken) Ixodoidea:Argasidae.Ph.D.Thesis, Ain Shams Univ.,Cairo,Egypt .

35. Mellin, T. N., Busch, R. D. and Wang, C. C. (1983): Postsynaptic inhibition of invertebrate neuromu scular transmission by avermectin $\mathrm{B}_{1} \mathrm{a}$. Neuropharmacology, 22: 89-96.

36. Nosek, J., Hoogstraal, H., Labuda, M. and Cyprich, D. (1980): Bionomics and health importance of fowl tick Argas (Persicargas) persicus (Oken, 1818) (Ixodoidea: Argasidae). Z. Parasitenkd., 63: 209-212.

37. Perez,S.J.;Grosman,C.;Urrea,P.M.A. ;Denegri,G.;Casado,N.andRodriguez, C.F.(2001):Depolarization of the tegument precedes morphological alte rations in Echinococcus granulosus protoscoleces incubated with iverm ectin. Parasitol Res Oct;87(10):804-7.

38. Pong, S. S. and Wang, C. C. (1979): Specific binding of avermectin $B_{1} a$ to brain synaptosomes. In: $11^{\text {th }}$ Int. Congr. Biochem., July 1979, Toronto.

39. Pong, S. S. and Wang, C. C. (1980): The specificity of high-affinity binding of avermectin $\mathrm{B}_{1}$ a to mammalian brain. Neuropharmacology, 19: 311-317.

40. Pong, S. S., Wang, C. C. and Fritz, L. C. (1980): Studies on the mechanism of action of avermectin $B_{1}$ a: stimulation of release of $\gamma$-aminobutyrate from brain synaptosomes. J. Neurochem., 34: 351358.

41. Raikhel, A. (1978): Ultrastructural aspects of oogenesis in the ixodid tick Hyalomma asiaticum. Tr. Zool. Inst. Akad. Nauka SSSR, 77: 37: 37-46.
42. Roshdy, M. A. (1967): Histochemical studies on the developing oocytes of the tick Argas persicus (Oken). Proc. Zool. Soc., UAR, 2: 11-26.

43. Schinkel, A. H., Wagenaar, E., van Deemter, L., Mol, C. A. and Borst, P. (1995): Absence of the mdrla Pglycoprotein in mice affects tissue distribution and pharmacokinetics of dexamethasone, digoxin, and cyclosporin A. J. Clin. Invest., 96(4): 1698-705.

44. Shanbaky, N. M. and Khalil, G. M. (1975): The subgenus Persicargas (Ixodoidea: Argasidae: Argas). 22. The effect of feeding on hormonal control of egg development in Argas (Persicargas) arboreus. Exp. Parasitol., 37: 361-366.

45. Smith,J.M. and Prichard,R.K. (2002): Localization of p-glycoprotein mRNA In the tissues of Haemonchus contotus adult worms and its relative abundance in drug-selected and susceptible strains.J.Parasitol Jun;88 (3):612-20.

46. Supavilai, P. and Karobath, M. (1981): In vitro modulation by averm ectin $\mathrm{B}_{1} \mathrm{a}$ of the GABA/benzodiazepine receptor complex of rat cerebellum. J. Neurochem., 36: 798-803.

47. Veraldi, S., Barbareschi, M., Zerboni, R. and Scarabelli, G. (1998): Skin manifestations caused by pigeon ticks (Argas reflexus). Cutis, 61(1): 38-40.

48. Wildenburg, G., Darge, K., Knab, J., Tischendorf, F. W., Bonow, I. and Büttner, D. W. (1994): Lymph nodes of onchocerciasis patients after treatment with ivermectin: reaction of eosinophil granulocytes and their cationic granule proteins.Trop. Med. Parasitol., 45: 87-96.

49. Yu Quan, H., ZhiYong, X., ChengLong, M., YQ, H., ZY, X. and CL, M. (1995): Report of Argas persicus attacking humans. Chinese J. Parasitol. Parasit. Dis., 13(2): 137. 


\section{التغيرات التركيبية الدقيقةوالهستولوجية المستحدثة بعقار الافرميكتين فى المئي

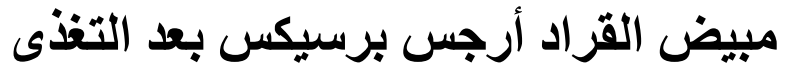

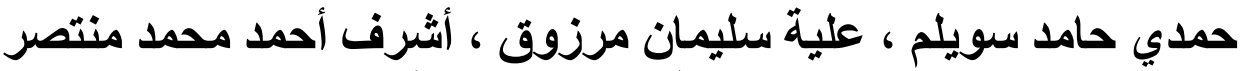

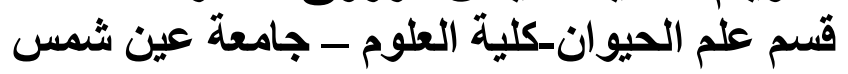

يتكون جدار المبيض فى القراد أرجس برسيكس من بويضات أولية فى ثلاث مر احل

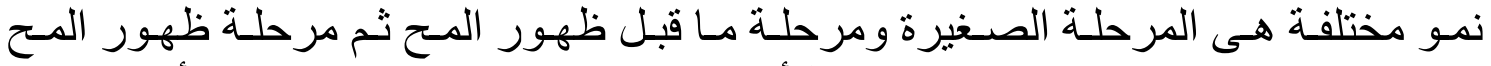

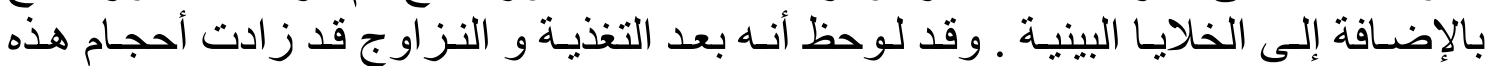

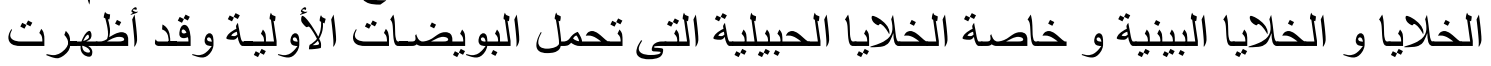

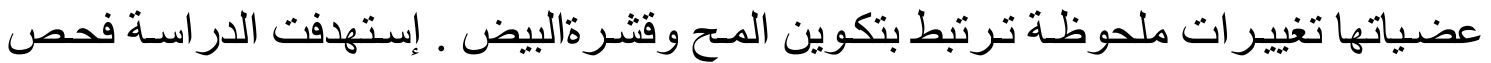

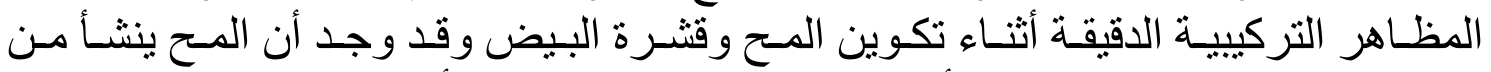

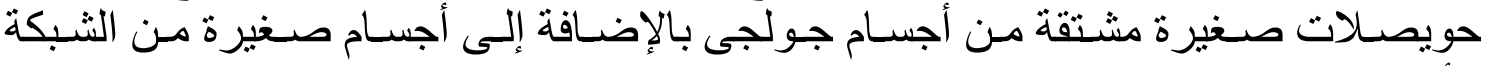

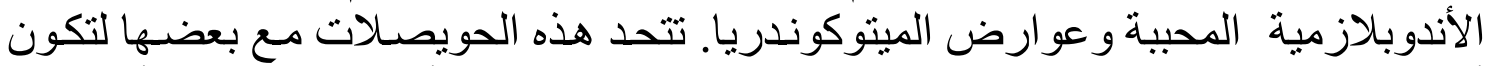

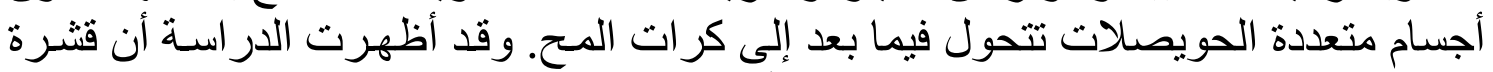

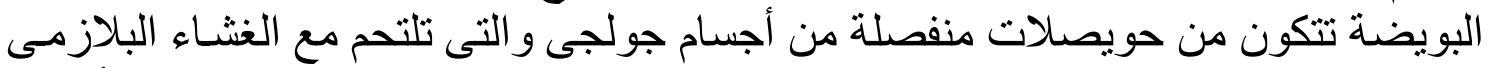

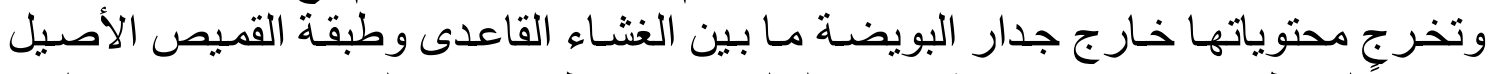

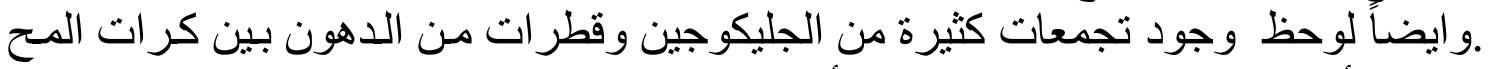

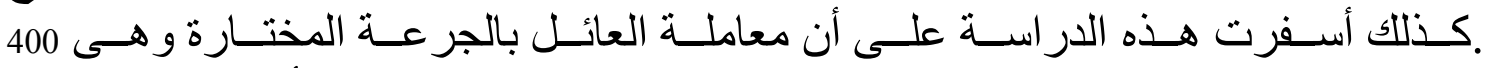

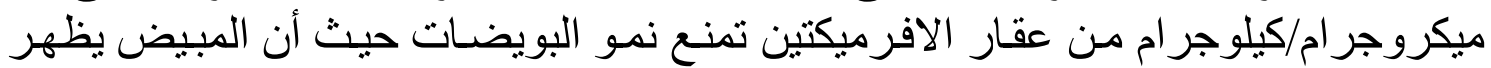

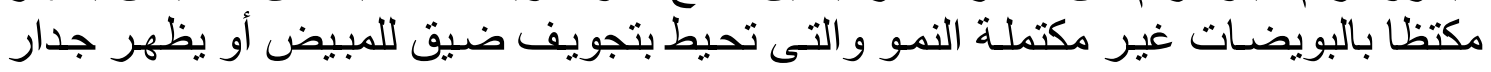

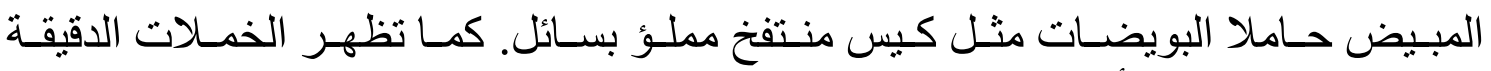

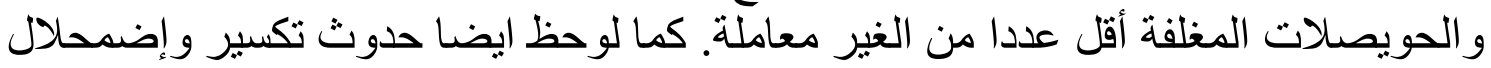

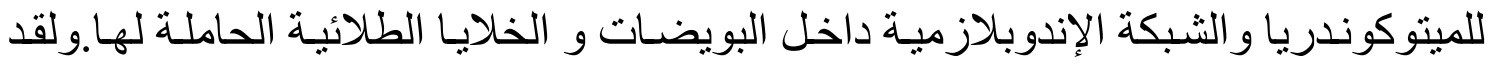

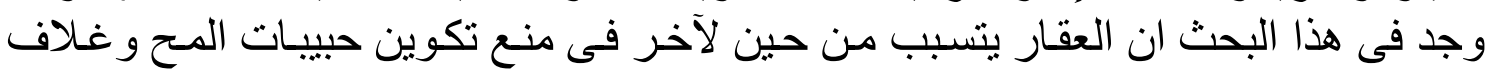

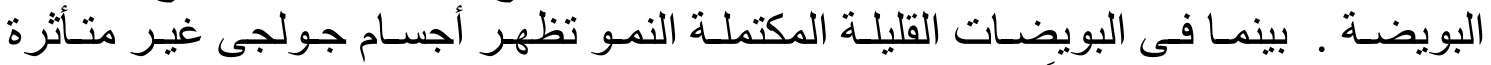

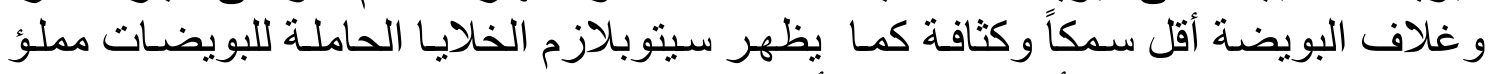

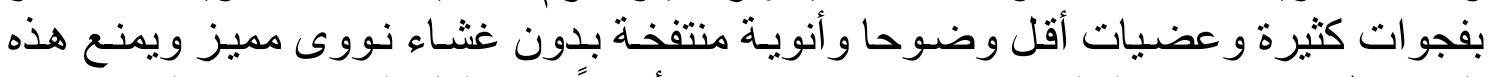

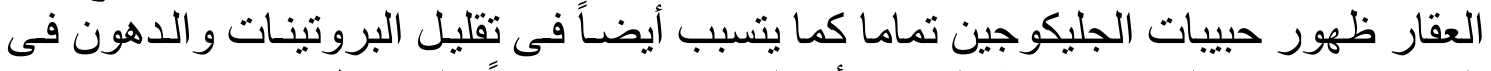

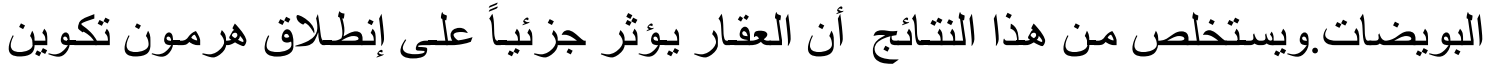

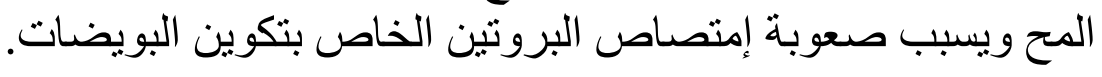

